\title{
Occurrence, distribution and ecological risk of trace metals and organic pollutants in surface sediments from a Southeastern European river (Someşu Mic River, Romania)
}

Badreddine Barhoumi ${ }^{\text {a,b }}$, Mihail Simion Beldean-Galea ${ }^{\text {b }}$, Abdulla M. Al-Rawabdeh ${ }^{\text {c }}$, Carmen Roba ${ }^{\text {b,d }}$, Ildiko Melinda Martonos ${ }^{\text {b }}$, Ramona Bălc ${ }^{\text {b }}$, Massoud Kahlaoui e, Soufiane Touil ${ }^{\text {a }}$, Marc Tedetti ${ }^{\text {f }}$, Mohamed Ridha Driss $^{\text {a }}$, Călin Baciu ${ }^{\text {b, * }}$

a Laboratory of Hetero-Organic Compounds and Nanostructured Materials (LR18ES11), Department of Chemistry, Faculty of Sciences of Bizerte, University of Carthage, 7021-Zarzouna, Tunisia

b Faculty of Environmental Science and Engineering, Babeș-Bolyai University, Fântânele Street, No. 30, 400294 Cluj-Napoca, Romania

${ }^{c}$ Department of Earth and Environmental Science, Yarmouk University, Irbid 21163, Jordan

${ }^{d}$ Research Institute for Sustainability and Disaster Management based on High Performance Computing (ISUMADECIP), Babeş-Bolyai University, Fântânele Street, No. 30, 400294 Cluj-Napoca, Romania

${ }^{\mathrm{e}}$ Laboratoire de physique des matériaux, Unité de service commun spectromètre de surfaces, Université de Carthage, Faculté des Sciences de Bizerte, Zarzouna, Bizerte 7021, Tunisia

${ }^{\mathrm{f}}$ Aix Marseille Univ., Université de Toulon, CNRS, IRD, MIO UM 110, 13288, Marseille, France

*Corresponding author. Phone: +40264307030 ;

E-mail: calin.baciu@ ubbcluj.ro

\section{Abstract}

In the present study, we investigated, for the first time, the distribution, sources and ecological risk of trace metals and organic pollutants, including polycyclic aromatic hydrocarbons (PAHs), polychlorinated biphenyls (PCBs) and organochlorine pesticides (OCPs), in surface sediments from a Southeastern European river (Someşu Mic River, Romania). Concentrations of $\mathrm{Cd}, \mathrm{Cr}, \mathrm{Cu}, \mathrm{Pb}, \mathrm{Ni}$ and $\mathrm{Zn}$ ranged from 0.04 to $0.4,9.4$ to $43.15,7.2$ to $65.6,12.3$ to $131.4,14.7$ to 47.7 and 42.1 to $236.8 \mathrm{mg} \mathrm{kg}^{-1}$ dw, respectively. Concentrations of total PAHs, PCBs and OCPs ranged from 24.8 to $575.6,2.7$ to 252.7 and 2.1 to $44.3 \mathrm{ng} \mathrm{g}^{-1} \mathrm{dw}$, respectively. 
Some sediment parameters, i.e., $\mathrm{pH}$, total organic carbon (TOC) and total organic matter (OM) contents, played a significant role in the spatial distribution of contaminants. A combined analysis based on diagnostic ratios and multivariate analyses revealed PAHs originating mainly from pyrolytic sources. PCB compositions showed distinct contamination signatures for tri- to tetra-chlorinated PCBs, characteristic of contamination by Aroclor1016 and -1254 technical mixtures. The dominant OCP congeners were $\alpha-\mathrm{HCH}$ and $p, p^{\prime}$-DDD, reflecting a past use of technical HCHs and DDTs in agricultural practices. Metal source and pollution status was assessed using geoaccumulation index and enrichment factor, which indicate a widespread pollution by $\mathrm{Pb}, \mathrm{Cd}, \mathrm{Zn}, \mathrm{Ni}$ and $\mathrm{Cu}$. The use of Sediments Quality Guidelines (SQGs), mean effect range-median quotient (m-ERM-Q) and toxic equivalent factor (TEF) indicated that the highest ecological risks occurred for PCBs and DDTs. This work presents not only initial baseline information on the extent of organic and inorganic contaminations in a river of ecological and economical interest, but also provides a diagnostic ratio/statistical combined approach that can be used to evaluate sediment quality in similar environments.

Keywords: Sediments, Metals, Organic pollutants, Risk assessment, Someşu Mic River

\section{Introduction}

As ecologically and economically important water bodies for human living, riverine ecosystems have attracted the interest of authorities and researchers, especially after the continuous development of urban, industrial and agricultural activities, which have released into these ecosystems large amounts of contaminants (Islam et al., 2015; Xu et al., 2016). Among these anthropogenic contaminants, metals, polycyclic aromatic hydrocarbons (PAHs) and persistent organic pollutants (POPs) such as polychlorinated biphenyls (PCBs) and organochlorine pesticides (OCPs) have caused deep concern for both developed and developing countries due to their toxicity, persistence, bioaccumulation, high long-range atmospheric transport and potentially adverse health effects on wildlife and humans (Kilunga et al., 2017; Resongles, 2014). Human activities such as mining, smelting, traffic emissions, industrial sewage and agriculture are the main sources of metals in sediments (Besser et al., 2008; Odhiambo et al., 2013). PAHs are introduced into the environment mainly through petrogenic (oily wastes and spills, bilge water, etc.) or pyrolytic sources (vehicular and industrial emissions, domestic heating, waste incineration, biomass and coal combustion) (Manoli et al., 2000; Soclo et al., 2000; 
Zhang et al., 2017). Despite their ban or restricted use, PCBs and OCPs are still found in various environmental matrices due to their low degradation (Syakti et al., 2013). Due to their stability in high temperatures and good electric conductivity, PCB congeners were widely used in a variety of industrial and commercial appliances (Diamond et al., 2010). OCPs were used as pesticides in agriculture and for insect and rodent control and in hull paints as an antifouling agent (Oliveira et al., 2016; Y1lmaz et al., 2016).

In addition to industrial direct spills and accidents, metals, PAHs and POPs can be emitted into rivers through atmospheric deposition, sewage outfalls, and urban, agricultural and industrial runoff (Zheng et al., 2008; Hosono et al., 2011; Y1lmaz et al., 2016). As a result of their hydrophobic characteristics, as well as their high affinity for organic matter, they tend to associate with suspended particles and are subsequently deposited to the sediments, which act as ultimate sinks and carrier media for these pollutants (Mwanamoki et al., 2014). The remobilization of surficial sediment-associated pollutants under certain environmental conditions (such as $\mathrm{pH}$, oxidation-reduction potential (Eh), salinity, flow turbulence, storms and flood events) and during human activities (such as dredging, dredge disposal and fishing), can pose potential risks to sediment dwelling organisms (Eggleton and Thomas, 2004; Matisoff et al., 2017; Xu et al., 2016). Therefore, surface sediments, which reflect the current contamination status, are considered an optimal medium to evaluate the environmental quality in rivers, estuarine and coastal ecosystems (Mwanamoki et al., 2014).

The Someşu Mic River (SMR), located in Northwest Romania, is a water body of important economic value; however, it is vulnerable to anthropogenic contaminations induced by the increasing urbanization and industrialization in recent years. Few studies have been carried out to evaluate the trace metals, PAHs and POPs levels in sediments from the riverine ecosystems of Romania (Beldean-Galea et al., 2016; Dragan et al., 2006; Levei et al., 2014; Matache et al., 2009; Neamtu et al., 2009). To the best of our knowledge, the present work is the first study investigating the occurrence, spatial distribution, potential sources and ecotoxicological risk of a large variety of trace metals, PAHs and POPs in surface sediments of the SMR.

\section{Material and methods}

\subsection{Study area and sampling sites}


The SMR, located in Northwest Romania, covers an area of $3733 \mathrm{~km}^{2}, 80 \%$ of which is located in the Neogene Transylvanian Basin and 20\% in the Apuseni Mountains (Perşoiu and Rădoane, 2011). It is formed at the junction of Someşu Cald and Someşu Rece Rivers (Fig. S1). At the junction of these two rivers, an artificial reservoir named Gilău was built in the 1960s. Between this reservoir and the Floreşti reservoir, the flow is diverted through an artificial channel, while the natural channel is partly abandoned. The river is approximately $100 \mathrm{~km}$ long and predominantly sinuous with short meandering reaches. It crosses the Cluj-Napoca city to reach after $80 \mathrm{~km}$ the Someşul Mare River, east of Dej city. Generally, it flows in the north direction and empties into the Tisa River, an affluent of the Danube. It is the most important freshwater reservoir for ClujNapoca city and plays a vital role in sustaining its rapid urban development. Their main tributaries include rivers Someşu Rece, Căpuşul, Feneș, Gârbău, Nadaș, Becaș, Valea Caldă, Maraloi, Borşa, Lonea, Lujerdiu, Mărului, Ornan, Lung, Ocna and Ungurașul.

The initial and terminal sections of the study area were Gilău and Apahida villages, respectively, with a total length of approximately $40 \mathrm{~km}$. The upstream section is for agricultural use, while the midstream and downstream sections are mixed with industrial, residential and agricultural uses with scattered factories (Fig. S1). The study area has a temperate continental climate with mean annual temperature and rainfall of $8.4{ }^{\circ} \mathrm{C}$ and $582 \mathrm{~mm}$, respectively.

Sampling sites were selected considering the morphology of the river and the location of different human activities around it, e.g., industries, urban activities and agriculture. Twenty samples were collected including 13 from the main stream (M1 to M13) and 7 from tributaries (T1 to T7) (Fig. S1). The distance between the sampling sites was approximately $0.2-5 \mathrm{~km}$. The M2 and M7 sites were situated in the mainstream before mixing with tributaries and M3, M8 and M9 were located in the mixed zone of the main stream and tributaries. T1 was considered as the control site located in a rural area, far from traffic and industrial units. The GPS coordinates and characteristics of the investigated sites are given in the supplementary information (SI) (Table S1).

\subsection{Sample collection and pretreatment}

A total of sixty surface sediment samples $(0-20 \mathrm{~cm})$ were collected in May 2017 from the twenty sampling sites (Fig. S1). Samples were collected in triplicate, by mixing individual small samples collected from an area 
of 2 to $4 \mathrm{~m}^{2}$ in each site, using a stainless steel shovel. Water depth of sites ranged from 0.04 to $2 \mathrm{~m}$. Once collected, the sediment samples were sealed in clean polyethylene bags, stored in a cool-box at $4{ }^{\circ} \mathrm{C}$ and transported to laboratory immediately for further analysis. A portion of the samples $(\sim 500 \mathrm{~g}) \mathrm{was}$ kept wet in freezer at $-20{ }^{\circ} \mathrm{C}$ for the particle size analysis, and another portion was oven-dried at $40{ }^{\circ} \mathrm{C}$, ground, sieved through a $2 \mathrm{~mm}$-mesh sieve to remove any large grains, roots or debris, homogenized and then frozen at -20 ${ }^{\circ} \mathrm{C}$ for chemical analyses.

\subsection{Sediment characterization}

Physicochemical parameters including temperature, salinity, electrical conductivity (EC), dissolved oxygen (DO) and $\mathrm{pH}_{\mathrm{H} 2 \mathrm{O}}(\mathrm{pH}$ of the water column above the sediments) were measured in situ at the sediment-water interface using a portable multimeter (multi 3320 WTW, Germany) equipped with a pH electrode (SenTix41 WTW, Germany), conductivity cell (TetraCon 325 WTW, Germany) and dissolved oxygen sensor (CellOx 325 WTW, Germany) (Table S2). The $\mathrm{pH}$ of sediments $\left(\mathrm{pH}_{\mathrm{sed}}\right)$ was measured by shaking an aliquot of dry sediment $(10 \mathrm{~g})$ in $25 \mathrm{~mL}$ of distilled water for $10 \mathrm{~min}$. The suspension was left to stand for $10 \mathrm{~min}$ and the $\mathrm{pH}$ of the supernatant was measured by the $\mathrm{pH}$-meter. The organic matter (OM) percent was measured by the loss of ignition method according to Abrantes et al. (1999). Briefly, after drying in an oven at $72{ }^{\circ} \mathrm{C}$ for $24 \mathrm{~h}$, the sediment was burned in the oven at $550{ }^{\circ} \mathrm{C}$ for $4 \mathrm{~h}$. Then, the amount of MO was calculated by the following equation:

$$
O M(\%)=[(A-B) / A] \times 100
$$

where A and B are the weights of dried sediment before and after combustion, respectively.

Total organic carbon (TOC) was determined by using an analyzer equipped with a module for solid samples (Multi N/C 2100, Analytik Jena AG, Germany). Before TOC measurement, the sediment samples were acidified with $\mathrm{HCl}(2 \mathrm{~N})$ for $16 \mathrm{~h}$ and dried in an oven for $3 \mathrm{~h}$ at $105{ }^{\circ} \mathrm{C}$ to remove the inorganic carbon (Juravle et al., 2016).

The sediment textures were determined based on the standard hydrometer method (Foth, 1991) using the current national standard protocols (STAS 1913/5-85 and SR EN 14688-2, 2005) and classified into three groups: clay (grain size $<0.002 \mathrm{~mm}$ ), silt (grain size $0.002-0.063 \mathrm{~mm}$ ), sand (grain size $0.063-2 \mathrm{~mm}$ ), and gravel (grain size 2-63 mm). This method is a combination of the sedimentation step applied for the fine 
particles and the sieving step applied for the coarse sediments. The obtained percentages were plotted on the ternary diagram, which contains 12 major textural classes, in order to convert the proportion of different grain size classes into sediment archetypal textures.

\subsection{Pollutant analysis}

Details on chemicals, analytical procedures and instrument methods used are presented in SI (Text S1). Briefly, metal analysis was performed by atomic absorption spectrometry (AAS), after microwave digestion of approximately $500 \mathrm{mg}$ of dry sediment using aqua regia ( $\mathrm{HCl}: \mathrm{HNO} 3,3: 1)$. For organic pollutant analysis (PAHs, PCBs and OCPs), sediment samples were spiked with a multistandard mixture containing surrogate standards for PAHs (Naph- $d_{8}$, Ace- $d_{10}$, Flu- $d_{10}$ and Per- $\left.d_{12}\right)$, PCBs and OCPs (CB-30, -155 and -198$)$, and extracted by sonication. The extracts were then purified using silica-alumina columns and the analysis of native pollutants was subsequently performed using gas chromatography coupled with a mass spectrometer (GC-MS) and an electron capture detector (GC-ECD). The analyzed compounds included 8 metals, 16 PAHs, 20 PCBs and 11 OCPs.

\subsection{Quality assurance and quality control $(Q A / Q C)$}

The analytical data quality was guaranteed through the implementation of laboratory QA and QC methods, including procedural blanks (all reagents without sample addition), external standards, internal deuterated standards, matrix spiked samples (non-deuterated standards spiked into sediment), and detection limits, as well as certified reference materials. Calibration standards solutions at different concentrations were used daily for instrument calibration. Blank samples and standard reference material were run in the same way as samples (between each batch of ten samples). Surrogate standards were added to all samples prior to extraction to quantify procedural recoveries. The recoveries of target compounds in the spiked samples and the surrogate recoveries are reported in Tables S3 and S4, respectively. Most of the analytes were not detected in blanks, except Nap, Acy, Ace, Fl, Phe, CB-18, CB-28, HCB, $\alpha-\mathrm{HCH}, \gamma-\mathrm{HCH}, \mathrm{Zn}$ and Fe. Their amounts were not significant relative to that of the sediment samples ( $<1 \%$ for PAHs and metals, $<10 \%$ for OCs). The results from blank samples were used to establish method detection limits (MDLs), which were determined as the average blank values with 3 times their standard deviations. For compounds that were not detected in blanks, 
MDLs were based on instrument detection limits (IDLs), calculated as a signal-to-noise ratio (S/N) of 3 (Wolska, 2002). The MDLs for PAHs and POPs were in the range of 0.09-1.10 and 0.01-0.20 ng $\mathrm{g}^{-1} \mathrm{dw}$, respectively (Table S3). If the concentration of a given compound in a sample was below its MDL/IDL, this compound was considered as not detected in the sample (below the limit of detection, <lod).

The whole analytical procedure was validated by analyzing certified reference materials (EC-3 and ERMCC141). Table S5 shows the results of the EC-3 and ERM-CC141. A good agreement between the analyzed values and certified levels was obtained for all compounds. Good recoveries were also obtained varying from $68.8 \pm 5.6 \%$ to $110.1 \pm 2.9 \%$ for PAHs, from $89.8 \pm 10.7 \%$ to $117.2 \pm 14.1 \%$ for OCs and from $83.2 \pm 8.0 \%$ to $110.2 \pm 7.5 \%$ for metals. All the data reported here were corrected for the blanks but not corrected for the recoveries.

\subsection{Data handling}

The targeted compounds analyzed in this study include 8 metals $(\mathrm{Cd}, \mathrm{Cr}, \mathrm{Cu}, \mathrm{Pb}, \mathrm{Ni}, \mathrm{Zn}, \mathrm{Mn}$ and $\mathrm{Fe}), 16$ PAHs (Nap, Acy, Ace, Fl, Phe, Ant, Flu, Pyr, BaP, Chr, BbF, BkF, BaP, DahA, BghiP and IcdP), 20 PCB congeners (CB-8, -18, -28, -52, -44, -66, -77, -101, -105, -118, -126, -128, -138, -153, -170, -180, -195, -206, 187 and -209), and 11 OCPs (HCB, $\alpha-, \beta-, \gamma-$ and $\delta$-HCH, $p, p^{\prime}-\mathrm{DDT}, o, p^{\prime}-\mathrm{DDT} ; p, p^{\prime}-\mathrm{DDE}, o, p^{\prime}-\mathrm{DDE}, p, p^{\prime}-\mathrm{DDD}$ and $o, p^{\prime}$-DDD), defined as $\Sigma$ metals, $\Sigma$ PAHs, $\Sigma$ PCBs and $\Sigma$ OCPs, respectively. DDTs or $\Sigma$ DDTs represent the sum of $p, p^{\prime}$-DDT, $o, p^{\prime}$-DDT; $p, p^{\prime}$-DDE, $o, p^{\prime}$-DDE, $p, p^{\prime}-\mathrm{DDD}$ and $o, p^{\prime}-\mathrm{DDD}$, and HCHs or $\Sigma$ HCHs represent the sum of $\alpha-, \beta-, \gamma-$ and $\delta-\mathrm{HCH}$. The classification of PAHs, PCBs, the molecular ratios of PAHs and OCPs, the metal geo-accumulation index (Igeo) and enrichment factor (EF), the sediment quality guidelines (SQGs) and mean effect range median quotient (m-ERM-Q), the BaP equivalent (BaPeq) concentrations and BaP toxic equivalency factors (TEFs), as well as TEFs for CB-77, $-126,-105$ and -118 , and the total toxic equivalent for PCBs (total TEQ), which are used to assess the contamination status of the SMR sediments and the potential adverse biological effects of both organics and metals on aquatic biota, are fully detailed/decribed in SI (Text

\section{S2; Tables S6, S7).}

Statistical analysis, including the pearson correlation matrix (PCM), principal component analysis (PCA) and hierarchical cluster analysis (HCA) were performed using XLSTAT 2013.5.01. The level of significance 
was set at $\mathrm{p} \leq 0.05$. Figures and maps were plotted using graph prism 5 and ArcGIS 10.5, QGIS, and SAGA software. Microsoft Excel, version 2010, was also used for calculations.

\section{Results and discussion}

\subsection{Sediment physicochemical characterization}

It is generally stated that the environmental fate and behavior of organic and metallic pollutants in sediments are influenced by the physicochemical properties of sediments, such as the size and OM content of sedimentary particles, as well as temperature, $\mathrm{pH}$ and salinity (Ahmed et al., 2017; Doong and Lin, 2004). At the sediment-water interface, temperature, EC and DO ranged from 12.0 to $19.5{ }^{\circ} \mathrm{C}, 157.7$ to $1148.0 \mu \mathrm{S} \mathrm{cm}{ }^{-1}$ and 4.3 to $16.8 \mathrm{mg} \mathrm{L}^{-1}$, respectively (Table S2). Very low values of salinity (0.0 to 0.5$)$ were recorded along the river, suggesting that the supply of fresh water in the environment is extremely high. The SMR sediment samples were dominated by clayey sand and were slightly-to-moderately alkaline, with $\mathrm{pH}_{\text {sed }}$ varying from 6.9 to 9.3 (mean of 8.07). The small difference between $\mathrm{pH}_{\mathrm{sed}}$ and $\mathrm{pH}_{\mathrm{H} 2 \mathrm{O}}(7.1-8.6)$ can be explained by various factors, including $\mathrm{CO}_{2}$ leakage, bacterial activity, oxido-redox equilibrium, tidal flooding, sediment composition, etc. (Basallote et al., 2012). TOC and OM contents were 0.62-2.25\% and 0.13-0.90\%, respectively. The lowest and the highest values of TOC and OM were observed in T1 (upstream section of the study area) and M13 (downstream section of the study area) sites, respectively. The urban, agricultural, and industrial wastewater discharges may reflect the high contents in TOC and OM of M13 site.

\subsection{Distribution and sources of metals}

The metal concentrations in SMR sediments, as well as the world average values of continental crust and Romanian legislation (RL) are presented in Table 1 . Concentrations ranged from $0.1-0.4 \mathrm{mg} \mathrm{kg}^{-1} \mathrm{dw}(\mathrm{Cd})$ to 11359-35661 mg kg${ }^{-1} \mathrm{dw}(\mathrm{Fe})$. Except $\mathrm{Cr}$ and $\mathrm{Fe}$, the mean metal concentrations were approximatel 1.16-1.78 times higher than their corresponding world average continental crust, indicating that they were related to anthropogenic inputs. This result was confirmed by the wide range of the coefficient of variation (CV), which varied from 40.2 to $141.4 \%$ (Table 1). In comparison to published data, the mean concentrations of metals recorded from SMR sediments were relatively low (Table S8). The mean concentrations of $\mathrm{Cd}, \mathrm{Cu}$ and $\mathrm{Zn}$ were 
consistent with those recorded in the sediments of the Yangtze and Yellow Rivers in China (Cheng et al., 2015a,b; Han et al., 2016; Zhang et al., 2009), but lower than those in Aries River (Romania) (Levei et al., 2014), Boriganga River (Bangladesh) (Mohiuddin et al., 2011), Dey River (Moroco) (Barakat et al., 2012) and Almandes River (Kooba) (Olivares-Rieumont et al., 2005). The mean values of $\mathrm{Cr}$ and $\mathrm{Pb}$ were similar to those in the Yangtze, Yellow and Aries Rivers, but much lower than those in the Boriganga, Dey and Almandes Rivers. The Ni and Mn contents were also similar to those found in the Aries River.

The spatial distribution patterns of the eight metals in the SMR sediments are presented in Fig. 1. Cd, Cr, and Ni had similar spatial distributions; the concentrations were low except for some sites at the midstream and downstream of the study area. Concentrations of $\mathrm{Cd}, \mathrm{Cr}$, and $\mathrm{Ni}$ were elevated at M6, very likely due to the presence of sewage from the diffused drains of Cluj-Napoca city. The highest concentrations of $\mathrm{Pb}$ and $\mathrm{Cu} / \mathrm{Zn}$ were found in M7 and M13, respectively. The intense traffic near M7, and the agricultural (pesticides and fertilizers) and industrial activities near M13 are probably the main sources of $\mathrm{Pb}, \mathrm{Cu}$ and $\mathrm{Zn}$. The highest concentrations of $\mathrm{Mn}$ and Fe were found in M3, located $100 \mathrm{~m}$ downstream of the Floresti reservoir, suggesting that accumulated agricultural runoff in this reservoir (through the lona stream) could be a pollution source of these two metals. Metal concentrations ( sum of $\mathrm{Cd}, \mathrm{Cr}, \mathrm{Cu}, \mathrm{Pb}, \mathrm{Ni}, \mathrm{Zn}$ ) in samples collected from the main stream of SMR followed the descending order of site M13 > M7 > M6 > M4 > M10 > M9 > M5 > M8 > M3 > M11 > M12 > M1 > M2. Interestingly, this decreasing order of metals among the sampling sites did not follow a downstream pattern, which might be due to the metal input in sediments from site-specific characteristics (Ahmad et al., 2010). For example, M4 is located upstream of SMR but its levels of metals were higher than those at some downstream sites, such as M11 and M12.

The strong spatial variability of metal concentrations observed here may be attributed to different types of pollution sources and multiple factors including adsorption, flocculation, and physicochemical and hydrodynamic conditions (Jain et al., 2008; Wang et al., 2015; Yin et al., 2011). Metal concentrations observed in T1-T7 were lower than those found in the main stream (Fig. 1), indicating that these tributaries (Somesul Rece, Lona stream and Nadas River) were not important sources of metals for the SMR. Although the latter undergoes an important anthropogenic pressure (intense traffic, agricultural runoff, industrial and domestic sewage), the metal concentrations measured in this work are overall quite low relative to those recorded in other anthropogenically impacted river systems. This can be explained by the extremely low salinity measured 
throughout the SMR (mean of 0.13). Metals tend indeed to be "washed" from sediment particles in low salinity environments (<10), as opposed to areas with high salinity (Kumar et al., 2015).

To determine the source and contamination pathway of metals in surface sediments, statistical analyses including PCM and PCA were carried out. The results of PCM (Table S9) showed that the most of studied metals were significantly correlated with each other $(\mathrm{p}<0.05)$, suggesting that they could potentially result from the same sources of pollution (Pan et al., 2016). For Mn, the only significant correlation was observed with Fe, indicating that the adsorption capacity of Mn may be inhibited due to the competitive adsorption of other coexisting metal(loid)s in sediments (Zhang and Zheng, 2007). The absence of a strong correlation among the element pairs of $\mathrm{Cu}-\mathrm{Cd}, \mathrm{Cu}-\mathrm{Ni}, \mathrm{Fe}-\mathrm{Cu}$, and $\mathrm{Fe}-\mathrm{Pb}$ suggested that the concentrations of these metals were not controlled by a single factor and they may have different anthropogenic as well as natural sources (Liu et al., 2017).

PCA factor loadings were calculated to better understand the relationship among metals and distinguish their possible sources in SMR sediments (Table S10). Two factors with eigenvalues > 1 were extracted, which accounted for $77.2 \%$ of the dataset total variance. Therefore, these two factors play an important role in explaining the level of contamination by metals along with their potential sources in the present area. The first Factor (Factor 1, eigenvalue 4.52) explained 56.6\% of the total variance and had strong positive loadings (>0.70) on $\mathrm{Cd}, \mathrm{Cr}, \mathrm{Ni}$, and $\mathrm{Zn}$, and a moderate positive loading on $\mathrm{Cu}, \mathrm{Pb}$, and $\mathrm{Fe}$, which is in agreement with the results of PCM (Table S9). This factor represents mainly anthropogenic sources, with influences of natural sources. These anthropogenic elements $(\mathrm{Cd}, \mathrm{Cr}, \mathrm{Ni}, \mathrm{Zn}, \mathrm{Cu}$ and $\mathrm{Pb})$ are derived from different activities around the river (automobile exhaust, car lubricants, batteries, electrical apparatuses, lacquer cosmetics and paints) and can enter the river system through atmospheric deposition, municipal runoffs, and domestic and industrial effluents (Chen et al., 2005; Fu et al., 2014; Micó et al., 2006). Factor 2 (eigenvalue 1.65), which accounted for $20.6 \%$ of the total variance, had strong positive loadings on Mn. This factor represents mainly natural sources. Fe element has moderate positive loading with F1 and F2, indicating that Fe in sediments was affected by both anthropogenic and natural sources.

The PCA loading plots of the first two factors presented in Fig. 2A shows that these elements could be classified into two groups, Group 1 with $\mathrm{Cd}, \mathrm{Cr}, \mathrm{Ni}, \mathrm{Zn}, \mathrm{Cu}$ and $\mathrm{Pb}$ elements, and Group 2 with $\mathrm{Mn}$ and $\mathrm{Fe}$ elements. The classification results are consistent with the results of PCA factor loadings. 


\subsection{Enrichment factor (EF) and geoaccumulation index (Igeo)}

EF and Igeo values for the selected eight metals in SMR sediment samples are presented in Fig. 3. As a standard procedure, EF and Igeo are an important indices used to discriminate anthropogenic and natural sources of metals, and assess the contamination level of the sediment (Adamo et al., 2005; Bastami et al., 2014; Cevik et al., 2009). As shown in Fig. 3, the mean Igeo values showed the decreasing order $\mathrm{Pb}>\mathrm{Cd}>\mathrm{Zn}>\mathrm{Ni}>$ $\mathrm{Cu}>\mathrm{Mn}>\mathrm{Cr}>\mathrm{Fe}$. The highest Igeo values were observed for $\mathrm{Pb}$ (2.13) and $\mathrm{Mn}$ (2.39) in sites M7 and M3, respectively, indicating moderately-to-strongly contaminated status for $\mathrm{Pb}$ and $\mathrm{Mn}$ in these two sites (Table 2). The range of Igeo values for the eight metals in all the other sites are between -2.42 and 1.15 , indicating uncontaminated to moderately contaminated status in SMR sediments. The mean Igeo values of the studied sites followed the order M7 > M6 > M13 > M4 > T6 > M3 > T5 > M10 > M5 > T7 > T4 > M9 > M1 > M8 > $\mathrm{M} 2>\mathrm{M} 11>\mathrm{M} 12>\mathrm{T} 3>\mathrm{T} 2>\mathrm{T} 1$. As shown above, the highest and the lowest contamination levels were observed in sites located in the midstream and the tributaries of SMR, respectively. Compared with the Romanian legislation (RL) (Table 1), SMR sediments are considered polluted with $\mathrm{Cu}, \mathrm{Pb}, \mathrm{Ni}$ and $\mathrm{Zn}$, which exceeded statutory limits in some sites (T4, T5, M4, M7, M9 and M13).

As suggested by Wang et al. (2008) $0.5 \leq \mathrm{EF} \leq 1.5$ indicates that the metal is entirely from crustal materials or natural processes, whereas EF>1.5 suggests that the sources are more likely to be anthropogenic. As shown in Fig. 3, the mean EF values for all studied metals except Cr were larger than 1.5 in the SMR sediments, suggesting that the anthropogenic source was dominant. Similar results were observed by Liu et al. (2017) in the sediments of the Xiangjiang River, China. The highest $\mathrm{EF}$ value for $\mathrm{Pb}$ was found in $\mathrm{M} 7$, indicating "severe enrichment," according to the classification criteria cited in Table 2. The highest EF values for $\mathrm{Cr} / \mathrm{Ni}, \mathrm{Cd}, \mathrm{Cu}$, $\mathrm{Zn}$, and Mn were observed in T5, T6, T4, M10, and M3, respectively, indicating "minor-to-moderately severe enrichment." Except Mn in M3 with an EF value of 7.70, the EF values for $\mathrm{Cr}$ and $\mathrm{Cu}$ are below 3 in all sites, indicating "minor enrichment." The mean $\mathrm{EF}$ values for metals followed the order $\mathrm{Pb}>\mathrm{Cd}>\mathrm{Cu}>\mathrm{Zn}>\mathrm{Ni}>$ $\mathrm{Mn}>\mathrm{Cr}$, and the mean EF values for sites followed the order M7 > T6 > M10 > M9 > T5 > T7 > T4 > M8 > $\mathrm{M} 13>\mathrm{M} 11>\mathrm{M} 2>\mathrm{M} 5>\mathrm{M} 6>\mathrm{M} 12>\mathrm{M} 1>\mathrm{M} 3>\mathrm{T} 3>\mathrm{M} 4>\mathrm{T} 1>\mathrm{T} 2$. Taken as a whole, the results of EF index suggested that $\mathrm{Pb}, \mathrm{Cd}, \mathrm{Cu}, \mathrm{Zn}$ and $\mathrm{Ni}$ could be originated from anthropogenic sources, whereas $\mathrm{Cr}$ and Mn might have originated from both natural and anthropogenic sources. 


\subsection{Distribution and sources of PAHs}

Concentrations of individual PAHs, $\Sigma$ CPAHs and PAHs are provided in Table 1. Except BaA and Ant, which were detected at low rates (5 and 30\% respectively), all PAHs were detected in most of sites, with a mean detection rate of $88 \%$. As listed in Table 1 , Flu (2.0 to $98.1 \mathrm{ng} \mathrm{g}^{-1} \mathrm{dw}$ ) exhibited the highest concentrations, followed by Pyr (1.4 to $99.6 \mathrm{ng} \mathrm{g}^{-1} \mathrm{dw}$ ), Chr (1.2 to $88.8 \mathrm{ng} \mathrm{g}^{-1} \mathrm{dw}$ ) and Phe (<lod to $90.5 \mathrm{ng} \mathrm{g}^{-1}$ dw). Their contributions to $\Sigma$ PAHs were 13.9, 12.7, 12.5 and 12.4\%, respectively (Fig. S2A). The presence of Flu, Pyr, Chr and Phe in high concentrations in sediments is in agreement with the data reported in the literature (Bi et al., 2018; Y1lmaz et al., 2016). The CVs of individual PAHs ranged from 61 to 447\%. These large CVs could reflect that the occurrence of PAHs in the SMR surface sediments might be related to anthropogenic activities along the river (Qian et al., 2017).

The spatial distributions of $\Sigma$ PAHs and $\Sigma$ CPAHs concentrations in the SMR surface sediments are shown in Fig. 4. The $\Sigma$ PAHs concentrations ranged from 24.8 to $575.6 \mathrm{ng} \mathrm{g}^{-1} \mathrm{dw}\left(233.2 \pm 161.3 \mathrm{ng} \mathrm{g}^{-1} \mathrm{dw}\right)$, showing a high spatial variability (Table 1). The highest concentration was observed in M13 (575.6 $\mathrm{ng} \mathrm{g}^{-1} \mathrm{dw}$ ) followed by T7 (508.6 $\mathrm{ng} \mathrm{g}^{-1} \mathrm{dw}$ ) and M11 (430.1 $\left.\mathrm{ng} \mathrm{g}^{-1} \mathrm{dw}\right)$, while the lowest one was recorded in T3 (24.8 $\left.\mathrm{ng} \mathrm{g}^{-1} \mathrm{dw}\right)$. The industrial activities near M13, the WWTP and airport near M11 and the urban activities near T7 could be the main causes of high PAH concentrations. Slightly higher concentrations of $\Sigma$ PAHs were also found in T6, M7 and M10, three sites characterized by densely populated urban areas and affected by traffic emissions, fuel consumption, and domestic sewage discharge. The low concentrations observed in T1-T4 and M1-M3 could be explained by fewer pollution sources in such agricultural cultivation regions. The concentrations of $\Sigma \mathrm{CPAHs}$ ranged from 2.7 (in T3) to $242.1 \mathrm{ng} \mathrm{g}^{-1} \mathrm{dw}$ (in M13), with a mean value of $100.8 \mathrm{ng} \mathrm{g}^{-1} \mathrm{dw}$, and shared similar distribution characteristics to $\Sigma$ PAHs concentrations. On average, they accounted for $41.9 \%$ of $\Sigma$ PAHs in all samples (Fig. S2B). These seven PAHs were the major contributors to $\Sigma$ PAHs in SMR surface sediments.

Table S11 presents the comparison of the total concentration of $\Sigma$ PAHs determined in this study with those reported in other rivers around the world. According to the classification of Baumard et al. (1998b), the pollution levels of the SMR surface sediments were low to moderate. The concentrations found here are similar to the levels found in the Don River (Russia), Ovia River (Nigeria), Chao Phraya River (Thailand) and Songhua River (China), and higher than those found in the Tisza River (Romania), Poxim River (Brazil) and Biobio 
River (Chile); however, they are far below those found in sediments of the Durance River (France), Urban River (Taiwan), Shanghai River network (China) and Jakarta's rivers (Indonesia). It is worth noting that this comparison must be treated with caution, as the geological characteristics of the sampling areas, the number of samples taken, and the number of PAHs analyzed may not be the same.

The composition patterns of PAHs by ring size in the SMR surface sediments are shown in Fig. S2C. Compositional patterns of PAHs were mainly MMW and HMW-PAHs, accounting for 39.1 and $35.3 \%$ of total PAHs, respectively. This is in agreement with results found in surface sediments from many freshwater and marine environments (Bi et al., 2018; Tu et al., 2018; Zhang et al., 2014). The dominance of MMW and HMW-PAHs at most sites was likely due to their strong hydrophobicity, and their resistance to degradation (Chen et al., 2004). Occasionally LMW PAHs were also high, such in T1 and T3, where $2+3$-rings PAHs accounted for more than half of total PAHs (up to 70.9\%), suggesting local petrogenic sources (e.g., oil leakage), deposit of PAHs by long-range atmospheric transport, or a combination of the two (Huang and Batterman, 2014).

Five specific PAH ratios were calculated to identify the sources of PAHs in SMR: Flu/(Flu+Pyr), $\mathrm{IcdP} /(\mathrm{IcdP}+\mathrm{BghiP}), \mathrm{BaP} / \mathrm{BghiP}, \mathrm{LMW} / \mathrm{HMW}$, and $\mathrm{C}^{*} \mathrm{PAHs} / \Sigma \mathrm{PAHs}$. The detailed interpretation of each ratio is shown in Table S6, whereas the calculated ratios are given in Table 4. The mean values of Flu/(Flu+Pyr), and LMW/HMW were 0.53 and 0.44, respectively, suggesting a pyrolytic origin of PAHs (Soclo et al., 2000; Yunker et al., 2002) (Table 4). The BaP/BghiP ratios (mean value 0.70) were higher than 0.6 in $50 \%$ of sites, however, suggesting PAHs of petrogenic origin (Zhao et al., 2015). The composition patterns of PAHs described above also demonstrate that concentrations of HMW-PAHs were higher than those of LMW-PAHs (Fig. S2C). This might be because pyrolytic PAHs generally have higher molecular weights (Soclo et al., 2000). The IcdP/(IcdP+BghiP) ratios were between $0.2-0.5$ in all sites, except in T2 and M4 (Table S6), suggesting that fuel combustion would contribute to significant amounts of PAHs in the SMR sediments (Yunker et al., 2002). This was confirmed by the C*PAHs/ $\mathrm{CPAHs}$ ratios (mean value 0.70 ), which were close to 1 (Ravindra et al., 2006). Therefore, the five diagnostic ratios indicated the dominance of pyrolytic origin of PAHs accompanied by a small petrogenic contribution. The combustion processes, specifically fossil fuel combustion, were very likely the main source of pyrogenic PAHs. 
The correlations among above five isomer ratios were also analyzed. The correlations between any two of Flu/(Flu+Pyr), IcdP/(IcdP+BghiP), BaP/BghiP, LMW/HMW, and C*PAHs/¿PAHs were low $(-0.075<\mathrm{r}<$ 0.402), except for the correlation between LMW/HMW and $\mathrm{C}^{*} \mathrm{PAHs} / \mathrm{PAHs}$ (Table S12). The correlation analysis revealed that molecular ratios were not a reliable tool to recognize PAH sources (due to the complexity of parameters determining PAHs distribution in sediments), and need multivariate statistical methods such as PCA, to better identify the PAH potential sources (Oyo-Ita et al., 2017).

Factor loadings of the dataset are listed in Table S10 and plotted in Fig. 2B. Most of the variance (62.8\%) of the dataset was explained by the first two factors. Factor 1, explaining $48.2 \%$ of the total variance, was characterized by high loadings (>0.70) of Nap, Phe, Flu, Pyr, Chr, BaP, IcdP, and BghiP, and moderate loadings (0.50-0.70) of Acy, Ant and BbF+BkF. According to previous reports, BbF, BkF, BaP, IcdP and BghiP (HMW PAHs) are indicators of vehicle emissions (Harrison et al., 1996; Larsen and Baker, 2003; Liu et al., 2009), whereas Nap and Acy (LMW PAHs) are indicators of petrogenic sources (petroleum spills) (Dobbins et al., 2006; Marr et al., 1999). Phe, Flu, Pyr, Ant and Chr are indicators of coal combustion (Agarwal et al., 2009; Harrison et al., 1996; Larsen and Baker, 2003; Zuo et al., 2007). Therefore, Factor 1 represented a combination of pyrolytic and petrogenic sources. Factor 2, accounting for $14.7 \%$ of total variance, was negatively dominated by Ace and BaA. In Fig. 2B, Ace and BaA are located in the lower right quadrant. They did not display any correlation with all other PAHs, suggesting that they may have different sources.

Overall, the above results demonstrated that PAHs in SMR sediments originated from mixed sources but with the dominance of the pyrogenic source. The latter may come mainly from fossil fuel combustion (vehicle emissions and coal combustion). In addition, incineration of uncontrolled landfills and industrial and urban emissions along the SMR could also result in the increase of PAH loadings through atmospheric deposition and freshwater runoff. In some SMR sites, petrogenic PAHs may come from petroleum spills and wastewater discharge containing greasy dirt.

\subsection{Distribution and sources of PCBS}

Table 5 presents the detection rates and the concentrations of individual PCBs, $\Sigma_{7} \mathrm{PCBs}, \Sigma_{\mathrm{DL}} \mathrm{PCBs}$ and ¿PCBs in the SMR surface sediments. As shown in Table 5, with the exception of CB-52, -206, -30 and -126, which were detected at low rates $(10,15,30$ and $35 \%$, respectively); the other congeners were detected in most 
of the sediment samples (mean of $87 \%$ ), demonstrating an ubiquitous contamination by PCBs in SMR. CB-8 was not detected in any sample. The congener profiles (Fig. S3A and Table 5) show that PCBs with lower degrees of chlorination (CB-18, -28, -66 and -77) dominated. On average these compounds together accounted for $49.1 \%$ of $\Sigma$ PCBs (Fig. S3A). This congener profile characteristic is similar to that of sediment in the Nanfei River (Liu et al., 2017) and Lake Dianchi in China (Wan et al., 2011). Industrial activities and microbial dechlorination may be important pathways for the origin of the lower chlorinated PCBs (Bzdusek et al., 2006; Yun et al., 2015).

The concentrations of $\Sigma \mathrm{PCBs}, \Sigma_{7} \mathrm{PCBs}$ and $\Sigma_{\mathrm{DL}} \mathrm{PCBs}$ in SMR surface sediments ranged from 2.7 to 252.7, 0.6 to 123.5 and 0.1 to $32.9 \mathrm{ng} \mathrm{g}^{-1} \mathrm{dw}$, respectively (Table 5 and Fig. 4). They showed similar spatial distributions (highest concentrations at S13 and lowest ones at T1) with important variations between the 20 sites, as indicated by their CVs, higher than $100 \%$ (Table 5). The most polluted sites were M10 (85.1 $\mathrm{ng}^{-1}$ $\mathrm{dw}), \mathrm{M} 11$ (174.1 $\left.\mathrm{ng} \mathrm{g}^{-1} \mathrm{dw}\right), \mathrm{M} 12\left(97.5 \mathrm{ng} \mathrm{g}^{-1} \mathrm{dw}\right)$ and M13 (252.7 $\left.\mathrm{ng} \mathrm{g}^{-1} \mathrm{dw}\right)$, located downstream from the SMR. The higher concentrations at these sites may originate from the midstream input, atmospheric deposition, and local emission sources (WWTP and airport). Similar to this work, studies from other parts of the world have also reported an increase in PCB concentrations in the riverine systems when the river passes through urban and/or industrial areas (Desmet et al., 2012; Lv et al., 2015). High PCB concentration was also observed at T5 (71.4 $\mathrm{ng} \mathrm{g}^{-1} \mathrm{dw}$ ), located on Nadas River before the confluence with SMR, close to dense urbanization and industrial activity that could explain the high contents of PCBs. While T3, T4, T6, T7 and S3-S9 sites were considered as moderately polluted (13.1-38.3 $\left.\mathrm{ng} \mathrm{g}^{-1} \mathrm{dw}\right), \mathrm{T} 1, \mathrm{~T} 2, \mathrm{~S} 1$ and S2 (2.7-9.0 $\left.\mathrm{ng} \mathrm{g}^{-1} \mathrm{dw}\right)$ were slightly polluted. The $\Sigma_{7} \mathrm{PCBs}$ accounted for $51.2 \%$ of $\Sigma \mathrm{PCBs}$, while the $\Sigma_{\mathrm{DL}} \mathrm{PCBs}$ accounted only for $15.3 \%$ of $\Sigma \mathrm{PCBs}$ (Fig. S3B). Further, $\Sigma_{7}$ PCBs concentrations were strongly correlated with $\Sigma$ PCBs $(r=0.997, \mathrm{p}<0.0001)$, which suggested that the indicator PCB was a group of relevant marker congeners for describing the pollution level and the variation trend of all PCB congeners (Su et al., 2018).

As demonstrated by several authors (Edgar et al., 2003; Wu et al., 1997), the transport and redistribution of PCBs in sediments can be affected by the geochemical characteristics of the sediment (e.g., pH, TOC content, particle size distributions). Table S9 shows that no significant correlations were observed between all physicochemical parameters and $\Sigma$ PCBs, except between temperature and $\Sigma$ PCBs. This result suggests that PCB distribution is probably influenced by other factors, such as local emission sources and the river flow rate. 
PCB concentrations in the present study were similar to those found in the Ravi River, Pakistan (2.7-202.3 ng $\mathrm{g}^{-1} \mathrm{dw}$ ) (Iwegbue, 2016), Liaohe River, China (24-158 $\mathrm{ng} \mathrm{g}^{-1} \mathrm{dw}$ ) (Dragan et al., 2006), Bahlui River, Romania (4.9-179.6 $\mathrm{ng} \mathrm{g}^{-1} \mathrm{dw}$ ) (Lv et al., 2015) and Forcados River, Nigeria (4.6-424.3 ng g ${ }^{-1} \mathrm{dw}$ ) (Syed et al., 2014). The concentrations were higher than those reported in the Daliao River estuary, China (0.8-7.3 ng g ${ }^{-1}$ dw) (Men et al., 2014), Chenab River, Pakistan (0.8-59.4 ng g ${ }^{-1}$ dw) (Mahmood et al., 2014), Durance River, France (0.03-13.3 $\mathrm{ng} \mathrm{g}^{-1} \mathrm{dw}$ ) (Kanzari et al., 2015) and Tonghui River, China (0.8-8.5 $\mathrm{ng} \mathrm{g}^{-1} \mathrm{dw}$ ) (Zhang et al., 2004), but slightly lower than those recorded in the Yellow River, China (nd-700 ng g ${ }^{-1} \mathrm{dw}$ ) (Su et al., 2018) and industrialized urban river, France (2.8-435.0 $\mathrm{ng} \mathrm{g}^{-1} \mathrm{dw}$ ) (Kanzari et al., 2014) (Table S11).

PCB composition patterns in the SMR sediments are shown in Fig. S3C. Nine PCB homologs (Di- to Deca-CBs) were analyzed here. On average, their trends in the sediments decreased in the following order: Tetra- $>$ Tri- $>$ Hexa- $>$ Penta- $>$ Hepta- $>$ Deca- $>$ Octa- $>$ Nona-CBs. Di-CBs represented by CB-8 congener were not detected. Tetra-CBs were the most dominant homologs with a proportion of $33.4 \%$ of $\Sigma$ PCBs, followed by Tri-CBs contributing to $29.2 \%$ of $\Sigma$ PCBs (Fig. S3C). This profile was consistent with many previous studies (Mahmood et al., 2014; Su et al., 2018). We must keep in mind that in our present study, only one octachlorobiphenyl congener (CB-195) and one nonchlorobiphenyl congener (CB-206) were determined in Octa-CB and Nona-CB homologues, respectively. Thus, the homologue result may have discrepancy from the true value. High concentrations of less chlorinated PCBs (Tri- + Tetra-CBs) in sites located near the urban areas might be caused by the urban and waste disposal activities. Their presence in rural sites such as T1-T3 and M1M3, however, are probably due to inputs into the river by atmospheric deposition, directly or followed by runoff, given that no local sources of PCBs in these sites. In fact, these congeners exhibit higher mobility in the atmosphere and aquatic environment (Men et al., 2014). The presence of higher-chlorinated PCBs (Hepta- to Nona-CBs, mean of $13.0 \%$ ) may be due to the discharge of untreated contaminants near the source (Hong et al., 2005).

Homologues cannot fully characterize the source of PCBs, so their possible sources in SMR surface sediments can be investigated further using PCA factor loadings (Table S10). Three factors were extracted with eigenvalues $>1$ that collectively explained $86.4 \%$ of the total variance. Factors 1,2 , and 3 accounted for 55.2, 24.7, and $6.4 \%$ of the total variance, respectively. The PCBs with low-to-medium chlorinated PCBs (Tri- to Hexa-CBs) were highly associated $(>0.70)$ to Factor 1 , whereas the higher chlorinated PCBs (Hepta- to Nona- 
CBs) were associated with Factor 2. The presence of Tri-CBs can be attributed to technical PCBs such as Aroclor 1016, which was dominated by three-chlorinated PCBs (Frame et al., 1996). The presence of TetraCBs can be attributed to Aroclor-1242 and -1248, the microbial degradation of higher-chlorinated PCBs and nearby manufacturing industries (Vanier et al., 1996; Zhou et al., 2012). The presence of Penta- and Hexa-CBs can be attributed to Aroclor-1254, whereas high chlorinated PCBs can be attributed to Aroclor-1260 and -1262 (Frame et al., 1996). Generally, the presence of these different homologs are related to various uses such as, painted surfaces, electrical equipment and other industries around SMR (Barakat et al., 2012; Dierking et al., 2009; UNIDO, 2008). Factor 3 was only loaded by CB-209, indicating that they may have different sources relative to the other PCBs. This suggestion was confirmed by Fig. 2C where CB-209 is projected separately. Furthermore, as shown in Fig. 2C, a triple cluster of significant correlations between PCB congeners can be clearly seen: CB-18, -28, -52, -44, -66, -77, -105 and -118 (0.561<r < 0.986, p < 0.05), CB-126, -138, -153, 170, -180, -195, -206 and $-197(0.450<\mathrm{r}<0.925, \mathrm{p}<0.05)$ and CB-101, $-128(\mathrm{r}=0.846, \mathrm{p}<0.05)$. This observation suggests that SMR have received PCBs coming from different sources. The SMR flows through the Cluj-Napoca city characterized by an important urban and industrial activities. Therefore, the river receives various industrial wastewater and municipal effluents either by direct disposal without any treatments or through different outfalls and natural drains. Downstream from the SMR, the WWTP and the airport can contribute a significant amounts of untreated effluent. These result in river enrichment by PCBs coming from different sources. In addition, PCB inputs into SMR sediment may also come from atmospheric deposition and run-off from contaminated soil in the surrounding area.

To identifying the history of Aroclor mixtures used in the area, PCB composition of the SMR surface sediments were compared with those of commercial mixtures (e.g., Aroclor-1016, -1221, -1232, -1242, -1248, 1254, -1260, and -1262; Breivik et al., 2002) (Fig. S4). The results indicated that Aroclor mixtures used in the area could be similar to Aroclor-1016 along with Aroclor-1254, -1248 and -1242.

\subsection{Distribution and sources of OCPs}

Table 5 summarizes the OCP data. The $\Sigma$ OCPs concentration in SMR sediments ranged from 2.1 to $44.3 \mathrm{ng}$ $\mathrm{g}^{-1} \mathrm{dw}$. The $\Sigma \mathrm{HCH}$ ranged from 0.8 to $11.9 \mathrm{ng} \mathrm{g}^{-1} \mathrm{dw}$, the $\Sigma$ DDTs from 1.0 to $39.2 \mathrm{ng} \mathrm{g}^{-1} \mathrm{dw}$ and the HCB from 0.2 to $1.3 \mathrm{ng} \mathrm{g}^{-1} \mathrm{dw}$. The DDT concentrations prevailed over those of $\mathrm{HCHs}$ and $\mathrm{HCB}$, reflecting the 
large-scale use of DDTs in Romania. In fact, the DDTs/HCHs and DDTs/HCB ratios were $>1$ at all sites (means of 5.0 and 35.2, respectively). DDTs accounted for $75.4 \%$ of $\Sigma$ OCPs, whereas HCHs and HCB accounted for $20.7 \%$ and $3.9 \%$ of $\Sigma$ OCPs, respectively (Fig. S5A). These results are in agreement with those found for soils in other Romanian regions (Covaci et al., 2002; Dragan et al., 2007; Ferencz and Balog, 2010). Among DDTs, $p, p^{\prime}$-DDE, $p, p^{\prime}$-DDT and $p, p^{\prime}$-DDD were to be found higher with a detection rate of $100 \%$, while in the case of $\mathrm{HCHs}$ isomers, $\alpha-\mathrm{HCH}$ was the most dominant isomer and was found in all sediment samples. $\delta$-HCH was not detected in any sample. A spatial distribution map of DDTs, HCHs and HCB at different sampling sites along the SMR is shown in Fig. 4. The highest concentrations were found at T6, S11, and S9, while the lowest ones were found at $\mathrm{T} 1$ and $\mathrm{T} 7$. The wide fluctuations observed in the total concentrations $(\mathrm{CVs}>50 \%)$ suggest different emission sources in SMR or a dilution by clean sediments. The results may also suggest that the high concentrations of pesticides are caused by inputs from urban, industrial and agricultural activities. A highly contaminated sampling site (T6) is located in the midstream of SMR near a densely populated urban area (heart of Cluj-Napoca city), where it receives important amounts of the contaminants through untreated municipal and domestic wastes. Higher levels of HCB and HCHs in sediments from sites S9 and S11, located downstream of SMR, near an area with important urban and industrial activities (Fig. S1) might be caused by the municipal, domestic and industrial waste from the city containing a high ontaminant load. The WWTP, landfill and surface runoff from the agricultural activities near S11 may be another source of pesticides. Contrary to PCBs, we observe significant positive correlations between OM/TOC and $\Sigma$ OCPs (Table S9), indicating that sediment OM and TOC could enhance the adsorption of these compounds and therefore affect their transport and redistribution in sediments. OCPs in SMR sediments samples were close to those found in the Bahlui River, Romania (Dragan et al., 2006), Ravi River, Pakistan (Syed et al., 2014) and River Po, Italy (Viganò et al., 2015), higher than those found in the Tonghui River, China (Zhang et al., 2004), Durance River and Arc River, France (Kanzari et al., 2012, 2015), but lower than those observed in tropical urban rivers, Congo (Kilunga et al., 2017) (Table S11).

With regard to the compositions of $\mathrm{HCHs}$ (Fig. S5B), it can be seen that $\alpha-\mathrm{HCH}$ had the major contribution to the $\Sigma \mathrm{HCH}(78.1 \%)$, followed by $\gamma-\mathrm{HCH}(12.8 \%)$ and $\beta-\mathrm{HCH}(9.1 \%)$. These results may lead to the conclusion that technical HCHs, i.e., 60-70\% $\alpha-\mathrm{HCH}, 5-12 \% \beta$-HCH and 10-12\% $\gamma$-HCH (Lee et al., 2001), with predominant $\alpha-\mathrm{HCH}$ isomer, were used in agricultural practices in this area instead of pure lindane $(\gamma$ - 
$\mathrm{HCH}$ ), this being consistent with the results obtained in other Romanian areas (Dragan et al., 2007; Ene et al., 2012) and other countries (Calvelo Pereira et al., 2010; Hu et al., 2009).

Four ratios were calculated to identify the sources of OCPs: $o, p^{\prime}-\mathrm{DDT} / p, p^{\prime}-\mathrm{DDT}$, (DDE+DDD)/ $2 \mathrm{DDT}$, DDD/DDE, and $\alpha-\mathrm{HCH} / \gamma-\mathrm{HCH}$ (Table 4). The detailed interpretation of each ratio is shown in Table S6. The composition of DDTs (Fig. S5C) shows that $p, p^{\prime}$-DDD (27.7\%), p,p'-DDE (26.9\%) and p,p'-DDT (26.7\%) are predominant, followed by $o, p^{\prime}$-DDD (10.6\%), $o, p^{\prime}$-DDE (5.2\%) and $o, p^{\prime}$-DDT (3.0\%). Similar composition were observed by Neamtu at al. (2009) in the Bahlui River, Romania. This composition is not similar to technical DDT mixtures (75\% p,p'-DDT, 15\% o,p'-DDT, 5\% p,p'-DDE and <5\% p,p'-DDD, Metcalf, 1973); however, $o, p^{\prime}$-DDT/p, $p^{\prime}$-DDT ratios (mean: 0.1) were all <0.9 (Table 4), underlining that technical DDTs have been used in this region (Qiu et al., 2005). The $\alpha-\mathrm{HCH} / \gamma-\mathrm{HCH}$ ratios (mean: 8.9) were $>4$ in most sampling sites, also demonstrating the use of technical $\mathrm{HCH}$ (Zhao et al., 2015), as mentioned above. The (DDE+DDD)/ 2 DDTs ratios (mean: 0.7 ) were all $>0.5$, suggesting that technical DDTs mostly originated from historical use (Hitch and Day, 1992), due to their ability to remain in the agricultural soil for a long time and remobilize through evaporation and runoff (Miglioranza et al., 2013). This result corroborates the fact that use of DDT was in Romania in 1983 (Dragan et al., 2006). DDT could be converted into DDE by biodegradation under aerobic conditions via dehydrochlorination and oxidation, and into DDD via reductive dechlorination under anaerobic conditions (Syed et al., 2014). The rate of conversion of DDTs to the metabolites in sediments depends on environmental factors such as sediment type, temperature, moisture and organic carbon content (Syed et al., 2013b). In the SMR, the prevalence of DDD over DDE (DDD/DDE >1 in $70 \%$ of samples) suggests that DDT degraded to DDD under anaerobic conditions (Liu et al., 2008).

PCA analysis (Table S10) showed that four factors were extracted and accounted for $87.2 \%$ of the total variance. Factor 1, which explains $44.7 \%$ of the total variance, was highly associated $(>0.70)$ with DDTs metabolites and $\alpha-\mathrm{HCH}$, indicating historical use of DDTs. $\alpha-\mathrm{HCH}$ is the most volatile isomer and its presence in SMR sediment could be explained by contamination through atmospheric transport and the deposit of isomers volatilized from treated agricultural soils (Dragan et al., 2007). Factor 2 (17.6\%) showed moderate loadings by $\beta-\mathrm{HCH}$, the thermodynamically most stable structure among the $\mathrm{HCH}$ isomers (Calvelo Pereira et al., 2010). Hence, their presence in this region may be due to their slow biodegradation in sediments. Accounting for $14.6 \%$ and $10.3 \%$ of the total variance, Factors 3 and 4 were mainly loaded by $o, p^{\prime}$-DDT and 
$\mathrm{HCB}$, respectively. In addition to their important industrial and urban sources, the presence of $o, p^{\prime}$-DDT in SMR may be related to the presence of numerous hospitals, potential sources of this compound, which was used in pharmaceutical formulations. HCB is a widespread contaminant that was employed in the production of synthetic rubber (ATSDR, 2013) and used as a pesticide; it is also a byproduct during the production of a variety of chlorinated compounds. Furthermore, HCB has also been released into the environment by waste incineration (Van-Birgelen, 1998) and in a variety of reactions where it persists because of its thermodynamic stability (Breivik et al., 2004). Currently, there are no commercial uses of HCB in Romania, but it can be released from certain thermal processes in the metallurgical industry and from motor vehicles and incineration. The significant correlations between $p, p^{\prime}$-DDT and $p, p^{\prime}$-DDE $(\mathrm{p}<0.05), p, p^{\prime}$-DDT and $p, p^{\prime}-\mathrm{DDD}(\mathrm{p}<0.05)$, indicated that $p, p^{\prime}$-DDE and $p, p^{\prime}$-DDD originated mainly from the degradation of $p, p^{\prime}$-DDT (Fig. 2D). Additionally, the significant correlations among $\alpha-\mathrm{HCH}, o, p^{\prime}$-DDE, $p, p^{\prime}$-DDE, $o, p^{\prime}$-DDD and $p, p^{\prime}$-DDD, indicated their similar sources. No significant correlations were observed between $o, p^{\prime}$-DDT and the other isomers, indicated different emissions sources.

\subsection{Relationships between different classes of pollutants and physicochemical parameters}

PCA and HCA were carried out to obtain a full picture of the relationships between the measured parameters and to discriminate the different sampling sites (Fig. 5). The PCA reorganized the original data into six main factors with eigenvalues $>1$ and the first two components accounted for $52.2 \%$ of the total variance. Factors 1 and 2 represented 35.1 and $17.1 \%$ of the total variability, respectively. The loadings for the variables (A) and the scores for sampling sites (B) are shown in Fig. 5. Taken as a whole, these results suggest that metal, PAH, PCB and OCP concentrations were influenced by physicochemical parameters, particularly $\mathrm{pH}_{\mathrm{sed}}$, TOC and OM. TOC and OM displayed significant positive correlations with $\mathrm{Cd}, \mathrm{Cr}, \mathrm{Ni}, \mathrm{Zn}, \mathrm{Fe}$ and $\sum$ OCPs (Fig. 5A and Table S9) indicating that the latter probably had a common sources and transport pathways, such as the urban surface runoff, combustion of fossil fuel and discharge of industrial and domestic wastes from the city of Cluj-Napoca. $\mathrm{pH}_{\text {sed }}$ showed significant or not significant negative correlations with all analyzed compounds (Table S9). These negative correlations can be explained by the fact that lower $\mathrm{pH}$ would decrease anoxic degradation rates and contribute to OM accumulation and consequently affect contamination levels (Shi et al., 2007). Except for correlations between clay vs Pb, silt vs Cd, ¿OCPs vs sand, ¿OCPs vs gravel, no apparent 
relationship was found between physicochemical parameters, analyzed compounds and grain size among sites, suggesting that the variations of these parameters were influenced by factors other than sedimentary grain size. Furthermore, the significantly positive correlations among compounds (Table S9) also revealed that they might have similar sources. For example, the correlation between $\sum$ PCBs and $\mathrm{Zn}$ may be due to the discharge of municipal wastewater (Feng et al., 1998). The results of cluster analysis (Figs. 5B and 5C) classify the study sites in three groups according to their contamination degree and physicochemical parameters. T1-T3 sites (group 1) were located in tributaries of SMR in low pollution areas. M1, M2, M8-M12, T4, T5, T7 (group 2) and M3-M7, M13 and T6 sites (group 3) (M3-M7, M13 and T6) were located in moderate-to-high pollution regions.

\subsection{Ecotoxicological concerns}

To evaluate the ecotoxicological aspect of sediment contamination, some published SQGs (ERL and ERM) and toxic equivalent factors of dioxin-like PCB congeners and PAHs were applied (Long et al., 1995; Nisbet and Lagoy, 1992; Van den Berg et al., 2006). Table 3 presents the SQGs for metals, PAHs, PCBs and OCPs, and identifies the number of sites in the three different ranges defined by ERL and ERM. The concentrations of $\mathrm{Cd}$ and $\mathrm{Cr}$ from all SMR sites were below the ERL, suggesting that these two metals may cause rare adverse biological effects to local benthic organisms. With respect to $\mathrm{Cu}, \mathrm{Pb}, \mathrm{Ni}$ and $\mathrm{Zn}, 10,6,12$ and 2 sample sites were between the ERL and the ERM, respectively, highlighting that biological effects related to these metals would occur occasionally at these sites. As none of the measured concentrations at any of the sampling sites exceeded the ERM values, their presence may not cause any adverse biological effects within the SMR. The PAH concentrations (individual and total) at all sites were much lower than ERL, indicating that the ecological risk of PAHs in the sediments was considerably low. As reported in Table 3, for PCBs and OCPs the SQGs refer only to $\Sigma$ PCBs, $p, p^{\prime}$-DDE, $p, p^{\prime}$-DDD, $p, p^{\prime}$-DDT and $\Sigma$ DDT. For $\Sigma$ PCBs, at 10 of 20 sites the concentrations were between the ERL and the ERM and one site exceeded ERM, suggesting potential ecological risk. Regarding OCPs, the highest potential ecological risk was observed for $p, p^{\prime}$-DDT, for which 16 sites were between the ERL and the ERM, and two sites exceeded ERM value. $p, p^{\prime}$-DDE, $p, p^{\prime}$-DDD and $\Sigma$ DDT in 70,85 and $95 \%$ of sites were between the ERL and the ERM, respectively, which indicates that adverse effects to the biota would occasionally be observed. 
To determine the possible biological effect of combined compounds, the m-ERM-Q for measured metals (except Mn and Fr, no given values) and DDTs (sum of $p, p^{\prime}$-DDE, $p, p^{\prime}$-DDD and $p, p^{\prime}$-DDT) were calculated according to the equation above (Long, 2006; Long et al., 1995), and their spatial distribution are shown in Fig. 6. For metals (Fig. 6A), the m-ERM-Q values ranged from 0.09 to 0.36 , suggesting a $21 \%$ probability of negative biological toxicity (Table 2). The highest potential risk was measured in M7, while the lowest was measured in T1. For DDTs (Fig. 6B), two sites (M13 and T5) presented 49\% probability of negative biological toxicity, with m-ERM-Q of 0.52 and 0.71 , respectively. The other sites presented $21 \%$ probability of toxicity $(0.02<\mathrm{m}-\mathrm{ERM}-\mathrm{Q}<0.45) . p, p^{\prime}$-DDT was the main contributor to m-ERM-Q values, accounting for $59.4 \%$ of DDTs.

Although the TEF concept was originally developed to assess the toxicity of abiotic samples to humans, it has proven very useful in assessing the toxicity of a variety of environmental samples, including sediment samples (Yang et al., 2009). The TEF and TEQ values determined here for PAHs and dioxin-like PCB in surface sediments are provided in Table S7. The total TEQ concentrations of $\Sigma$ PAHs ranged from 1.01 to 74.6 $\mathrm{ng} \mathrm{g}^{-1} \mathrm{dw}$, with a mean value of $28.0 \mathrm{ng} \mathrm{g}^{-1} \mathrm{dw}$ and were higher than those in surface sediments from the Songhua River (mean $13.2 \mathrm{ng} \mathrm{g}^{-1} \mathrm{dw}$ ) (Zhao et al., 2014). The total TEQ concentrations of $\sum$ CPAHs ranged from 0.9 to $68.5 \mathrm{ng} \mathrm{g}^{-1} \mathrm{dw}$, with a mean value of $26.4 \mathrm{ng} \mathrm{g}^{-1} \mathrm{dw}$. Seven carcinogenic PAHs were the main contributors (93.9\%) to total TEQ concentrations. Among the seven carcinogenic PAHs, DahA (32.9\%) and $\mathrm{BaP}(31.4 \%)$ were the major contributors to total TEQ concentrations of $\sum \mathrm{CPAHs}$, confirming the importance of using DahA and $\mathrm{BaP}$ as indicators of carcinogenic PAHs. The spatial distribution of total TEQ concentrations of $\Sigma$ PAHs is shown in Fig. S6. The highest value at site T7 was approximately 74-fold higher than the lowest value at T3. The total TEQ concentrations of dioxin-like PCB ranged from $5.54 \times 10^{-5}$ to $0.1245 \mathrm{ng} \mathrm{g}^{-1} \mathrm{dw}$ with a mean value of $0.014 \mathrm{ng} \mathrm{g}^{-1} \mathrm{dw}$ (Table S7). The highest levels were found at T7, M6 and M10, which were located around the industrial/urban areas, receiving large volumes of effluent via different drains (Fig. S6). The total TEQ values measured in this work were found to be lower than those reported from the sediments of the Tiber River (Montuori et al., 2016), Chenab River (Eqani et al., 2012b) and Ravi River (Syed et al., 2014).

\section{Conclusion}


The results obtained in this study revealed the first detailed analysis of trace metal, PAH and POP distributions in surface sediments collected from 20 sites in the Someşu Mic River, Romania. Metal levels were lower than or comparable to those found in other rivers around the world, although PAH and POPs levels were moderate. These pollutants exhibited high spatial variabilities, with the highest concentrations near industrial and densely populated areas and the lowest ones at rural sites. Industrial effluents, untreated urban effluents, automobile exhaust, painted surfaces, electronic-waste, WWTP, incineration of uncontrolled landfills, urban and agricultural runoff, atmospheric deposition and petroleum combustion could be the major sources for the investigated contaminants. Risk assessment based on SQGs, m-ERM-Q and TEF indicated that DDTs could pose the highest risks for benthic organisms followed by PCBs, whereas ecological risks from metals and PAHs were potentially low. Considering the great ecological and economical importance of the SMR, further works should be performed on the water, suspended particle matter and atmosphere, in order to complete the pollutant budget in this area and to deepen the understanding of their sources in the sediment.

\section{Conflict of interest}

The authors declare there are no conflicts of interest in this study.

\section{Acknowledgements}

This project was financially supported by the Agence universitaire de la Francophonie (AUF), in the framework of the "Eugen Ionescu" program, and the Tunisian Ministry of Higher Education, Scientific Research and Technology. The authors would like to thank Dr. Iuliana Breabăn from "Alexandru Ioan Cuza" University of Iaşi, for the support provided for the TOC analysis.

\section{Appendix A. Supplementary data}

Supplementary data to this article can be found online at https://doi. org/10.1016/j.scitotenv...

\section{References}


Abrantes, A., Pinto, F., Moreira, M., 1999. Ecology of polychaete Nereis diversicolor, in the Cannal de Mira (Ria de averio, Portugal). Population dynamics, production and oogenic cycle. Acta Oceanol. 20, 267283.

Adamo, P., Arienzo, M., Imperato, M., Naimo, D., Nardi, G., Stanzione, D., 2005. Distribution and partition of heavy metals in surface and subsurface sediments of Naples city port. Chemosphere 61, 800-809.

Agarwal, T., Khillare, P.S., Shridhar, V., Ray, S., 2009. Pattern, sources and toxic potential of PAHs in the agricultural soils of Delhi, India. J. Hazard. Mater. 163, 1033-1039.

Ahmad, M.K., Islam, S., Rahman, S., Haque, M.R., Islam, M.M., 2010. Heavy metals in water, sediment and some fishes of Buriganga River, Bangladesh. Int. J. Environ. Res. 4, 321-332.

Ahmed, M.M., Doumenq, P., Awaleh, M.O., Syaktib, A.D., Asia, L., Chiron, S., 2017. Levels and sources of heavy metals and PAHs in sediment of Djibouti-city (Republic of Djibouti). Mar. Pollut. Bull. 120, 340346.

ATSDR, 2013. Toxicological Profile for Hexachlorobenzene, Atlanta, Georgia.

Barakat, A., El Baghdadi, M., Rais, J., Nadem, S., 2012. Assessment of heavy metal in surface sediments of Day River at Beni-Mellal region, Morocco. Res. J. Environ. Earth Sci. 4, 797-806.

Barakat, A.O., Mostafa, A., Wade, T.L., Sweet, S.T., El Sayed, N.B., 2012. Spatial distribution and temporal trends of persistent organochlorine pollutants in sediments from Lake Maryut, Alexandria, Egypt. Mar. Pollut. Bull. 64, 395-404.

Barra, R., Quiroz, R., Saez, K., Araneda, A., Urrutia, R., Popp, P., 2009. Sources of polycyclic aromatic hydrocarbons (PAHs) in sediments of the Biobio River in south central Chile. Environ. Chem. Lett. 7, $133-139$.

Basallote, M.D., Rodriguez-Romero, A., Blasco, J., Del Valls, A., Riba, I., 2012. Lethal effects on different marine organisms, associated with sediment-seawater acidification deriving from $\mathrm{CO}_{2}$ leakage. Environ. Sci. Pollut. Res. 19, 2550-2560.

Bastami, K.D., Bagheri, H., Kheirabadi, V., Zaferanid, G.G., Teymori, M.B., Hamzehpoor, A., Soltani, F., Haghparast, S., Harami, S.R.M., Ghorghani, N.F., Ganjih, S., 2014. Distribution and ecological risk assessment of heavy metals in surface sediments along southeast coast of the Caspian Sea. Mar. Pollut. Bull. 81, 262-267. 
Baumard, P., Budzinski, H., Garrigues, P., 1998a. PAHs in Arcachon Bay, France: origin and biomonitoring with caged organisms. Mar. Pollut. Bull. 36, 577-586.

Beldean-Galea, M.S., Mihăiescu, R., Arghiuş, V., Croitoru, A., Horvath, C., Coman, V., 2016. Occurrence and Sources of Polycyclic Aromatic Hydrocarbons in the Tisza River and its Romanian Tributaries. Water Air Soil Pollut. 227:377.

Besser, J.M., Brumbaugh, W.G., Ivey, C.D., Ingersoll, C.G., Moran, P.W., 2008. Biological and chemical characterization of metal bioavailability in sediments from Lake Roosevelt, Columbia River, Washington, USA. Arch. Environ. Contam. Toxicol. 54, 557-570.

Bi, C., Wang, X., Jia, J., Chen, Z., 2018. Spatial variation and sources of polycyclic aromatic hydrocarbonsinfluenced by intensive land use in an urbanized river network of East China. Sci. Total Environ. 627, 671-680.

Birch, G., 2003. Ascheme for assessing human impacts on coastal aquatic environments using sediments. In: Woodcoffe, C.D., Furness, R.A. (Eds), Coastal GIS, Wollongong University Papers in Center for Marinetime Pollicy, 14, Austrailia. http://www.ozestuaries.org/indicators/DEF_sedement_scheme.html.

Boonyatumanond, R., Wattayakorn, G., Togo, A., Takada, H., 2006. Distribution and origins of polycyclic aromatic hydrocarbons (PAHs) in riverine, estuarine, and marine sediments in Thailand. Mar. Pollut. Bull. $52,942-956$.

Breivik, K., Alcock, R., Li, Y., Bailey, R.E., Fiedler, H., Pacyna, J.M., 2004. Primary sources of selected POPs: regional and global scale emission inventories. Environ. Pollut. 128, 3-16.

Breivik, K., Sweetman, A., Pacyna, J.M., Jones, K.C., 2002. Towards a global historical emission inventory for selected PCB congeners - a mass balance approach 1. Global production and consumption. Sci. Total. Environ. 290, 181-198.

Bzdusek, P.A., Jianhang Lu, A., Christensen, E.R., 2006. PCB congeners and dechlorination in sediments of Sheboygan River, Wisconsin, determined by matrix factorization. Environ. Sci. Technol. 40, 120-129.

Calvelo Pereira, R., Monterroso Martínez, M.C., Martínez Cortízas, A., Macías, F., 2010. Analysis of composition, distribution and origin of hexachlorocyclohexane residues in agricultural soils from NW Spain. Sci. Total Environ. 408, 5583-5591.

Cevik, F., Goksu, M.Z.L., Derici, O.B., Fındık, Ö., 2009. An assessment of metal pollution in surface sediments 
of Seyhan dam by using enrichment factor, geoaccumulation index and statistical analyses. Environ. Monit. Assess. 152, 309-317.

Chen, B.L., Xuan, X.D., Zhu, L.Z.,Wang, J., Gao, Y.Z., Yang, K., Shen, X.Y., Lou, B.F., 2004. Distributions of polycyclic aromatic hydrocarbons in surface waters, sediments and soils of Hangzhou City, China. Water Res. 38, 3558-3568.

Chen, T.B., Zheng, Y.M., Lei, M., Huang, Z.C., Wu, H.T., Chen, H., Fan, K.K., Yu, K.,Wu, X., Tian, Q.Z., 2005. Assessment of heavy metal pollution in surface soils of urban parks in Beijing, China. Chemosphere 60, 542-551.

Cheng, H., Li, M., Zhao, C., Yang, K., Li, K., Peng, M., Yin, G., 2015a. Concentrations of toxic metals and ecological risk assessment for sediments of major freshwater lakes in China. J. Geochem. Explor. 157, $15-26$.

Cheng, Q., Wang, R., Huang, W., Wang, W., Li, X., 2015b. Assessment of heavy metal contamination in the sediments from the Yellow River Wetland National Nature Reserve (the Sanmenxia section), China. Environ. Sci. Pollut. Res. Int. 22, 8586-8593.

Covaci, A., Manirakiza, P., Schepens, P., 2002. Persistent organochlorine pollutants in soils from Belgium, Italy, Greece, and Romania. Bull. Environ. Contam. Toxicol. 68, 97-103.

Desmet, M., Mourier, B., Mahler, B.J., Van Metre, P.C., Roux, G., Persat, H., Lefèvre, I., Peretti, A., Chapron, E., Simonneau, A., Miège, C., Babut, M., 2012. Spatial and temporal trends in PCBs in sediment along the lower Rhône River, France. Sci. Total Environ. 433, 189-197.

Diamond, M.L., Melymuk, L., Csiszar, S.A., Robson, M., 2010. Estimation of PCB stocks, emissions, and urban fate: will our policies reduce concentrations and exposure? Environ. Sci. Technol. 44, 2777-2783.

Dierking, J., Wafo, E., Schembri, T., Lagadec, V., Nicolas, C., Letourneur, Y., Harmelin-Vivien, M., 2009. Spatial patterns in PCBs, pesticides, mercury and cadmium in the common sole in the NW Mediterranean, Sea, and a novel use of contaminants as biomarkers. Mar. Pollut. Bull. 58, 1605-1614.

Dobbins, R.A., Fletcher, R.A., Benner Jr, B.A., Hoeft, S., 2006. Polycyclic aromatic hydrocarbons in flames, in diesel fuels, and in diesel emissions. Combust. Flame 144, 773-781.

Doong, R., Lin, Y., 2004. Characterization and distribution of polycyclic aromatic hydrocarbon contaminations in surface sediment and water from Gao-ping River, Taiwan. Water Res. 38, 1733-1744. 
Dragan, D., Cucu-Man, S., Dirtu, A.C., Mocanu, R., Van Vaeck, L., Covaci, A., 2006. Occurrence of organochlorine pesticides and polychlorinated biphenyls in soils and sediments from Eastern Romania. Int. J. Environ. Anal. Chem. 86, 833-842.

Dragan, D., Cucu-Man, S., Mocanu, R., Covaci, A., 2007. Accelerated solvent extraction method for the determination of polychlorinated biphenyls and organochlorine pesticides in soils. Rev. Roum. Chim. 52, 597-601.

Edgar, P.J., Hursthouse, A.S., Matthews, J.E., Davies, I.M., 2003. An investigation of geochemical factors controlling the distribution of PCBs in intertidal sediments at a contamination hot spot, the Clyde Estuary, UK. Appl. Geochem. 18, 327-338.

Eggleton, J., Thomas, K.V., 2004. A review of factors affecting the release and bioavailability of contaminants during sediment disturbance events. Environ. Int. 30, 973-980.

Ene, A., Bogdevich, O., Sion, A., 2012. Levels and distribution of organochlorine pesticides (OCPs) and polycyclic aromatic hydrocarbons (PAHs) in topsoils from SE Romania. Sci. Total Environ. 439, 76-86.

Eqani, S.A.M.A.S., Malik, R.N., Zhang, G., Mohammad, A., Chakraborty, P., 2012b. Polychlorinated biphenyls (PCBs) in the sediments of the River Chenab. Pakistan Chem. Ecol. 28, 327-339.

Ergin, M., Saydam, C., Basturk, O., Erdem, E., Yoruk, R., 1991. Heavy metal concentrations in surface sediments from the two coastal inlets (Golden Horn Estuary and Izmit Bay) of the northeastern sea of Marmara. Chem. Geol. 91, 269-285.

Feng, H., Cochran, J.K., Lwiza, H., Brownawell, B.J., Hirschberg, D.J., 1998. Distribution of heavy metal and PCB contaminants in the sediments of an urban estuary: the Hudson River. Mar. Environ. Res. 45, 69-88.

Ferencz, L., Balog, A., 2010. A pesticide survey in soil, water and foodstuffs from Central Romania. Carpath. J. Earth Environ. Sci. 5, 111-118.

Foth, H.D., 1991. Fundamental of soil science, Eighth Ed. Wiley \& Sons, New York, 360p.

Frame, G.M., Cochran, J.W., Bøwadt, S.S., 1996. Complete PCB congener distributions for 17 aroclor mixtures determined by 3 HRGC systems optimized for comprehensive, quantitative, congener-specific analysis. J. High Resolut. Chromatogr. 19, 657-668.

Fu, J., Zhao, C., Luo, Y., Liu, C., Kyzas, G.Z., Luo, Y., Zhao, D., An, S., Zhu, H., 2014. Heavy metals in surface sediments of the Jialu River, China: Their relations to environmental factors. J. Hazard Mater. 
$270,102-109$.

Han, D., Cheng, J., Hu, X., Jiang, Z., Mo, L., Xu, H., Ma, Y., Chen, X., Wang, H., 2016. Spatial distribution, risk assessment and source identification of heavy metals in sediments of the Yangtze River Estuary, China. Mar. Pollut. Bull. 115, 141-148.

Harrison, R.M., Smith, D.J.T., Luhana, L., 1996. Source apportionment of atmospheric polycyclic aromatic hydrocarbons collected from an urban location in Birmingham, U.K. Environ. Sci. Technol. 30, 825-832.

Hitch, R.K., Day, H.R., 1992. Unusual persistence of DDT in some western USA soils. Bull. Environ. Contam. Toxicol. 48, 259-264.

Hong, S.H., Yim, U.H., Shim, W.J., Oh, J.R., 2005. Congener-specific survey for polychlorinated biphenlys in sediments of industrialized bays in Korea: Regional characteristics and pollution sources. Environ. Sci. Technol. 39, 7380-7388.

Hosono, T., Su, C.C., Delinom, R., Umezawa, Y., Toyota, T., Kaneko, S., Taniguchi, M., 2011. Decline in heavy metal contamination in marine sediments in Jakarta Bay, Indonesia due to increasing environmental regulations. Estuar. Coast Shelf Sci. 92, 297-306.

Hu, G.J., Chen, S.L., Zhao, Y.G., Sun, C., Li, J., 2009. Wang H. Persistent toxic substances in agricultural soils of Lishui County, Jiangsu Province, China. Bull. Environ. Contam. Toxicol. 82, 48-54.

Hu, J., Zheng, M., Liu, W., Li, C., Nie, Z., Liu, G., Xiao, K., Dong, S., 2013. Occupational exposure to polychlorinated dibenzo-p-dioxins and dibenzofurans, dioxin-like polychlorinated biphenyls, and polychlorinated naphthalenes in workplaces of secondary nonferrous metallurgical facilities in China. Environ. Sci. Technol. 47, 7773-7779.

Huang, L., Batterman, S.A., 2014. Multimedia model for polycyclic aromatic hydrocarbons (PAHs) and nitroPAHs in Lake Michigan. Environ. Sci. Technol. 48, 13817-13825.

IARC, 1987. IARC monographs on the evaluation of the carcinogenic risk of chemicals to humans. Overall evaluation of carcinogenicity: an updating of IAPC monographs (vol. 1-42). Lyon: International Agency for Research on Cancer. Suppl. 7.

Islam, M.S., Ahmed, M.K., Raknuzzaman, M., Habibullah-Al-Mamun, M., Islam, M.K., 2015. Heavy metal pollution in surface water and sediment: a preliminary assessment of an urban river in a developing country. Ecol. Indic. 48, 282-291. 
Iwegbue, C.M.A., 2016. Distribution and ecological risks of polychlorinated biphenyls (PCBs) in surface sediment of the Forcados River, Niger Delta, Nigeria. Afr. J. Aquat. Sci. 41, 51-56.

Jain, C.K., Gupta, H., Chakrapani, G.J., 2008. Enrichment and fractionation of heavy metals in bed sediments of River Narmada, India. Environ. Monit. Assess. 141, 35-47.

Juravle, D.T., Chira, C.M., Mare, S., Ionesi, V., Bulgariu, D., Breabăn, I.G., Juravle, A., 2016. Events in the Northern Paleogene Foreland Basin of the Eastern Carpathians (Romania, Bucovina), at the YpresianLutetian transition, Carpath. J. Earth. Env. 11, 131-146.

Kanzari, F., Laurence, A., Syakti, A.D., Piram, A., Malleret, L., Mille, G., Doumenq, P., 2015. Distribution and risk assessment of hydrocarbons (aliphatic and PAHs), polychlorinated biphenyls (PCBs), and pesticides in surface sediments from an agricultural river (Durance) and an industrialized urban lagoon (Berre lagoon), France. Environ. Monit. Assess. 187:591.

Kanzari, F., Syakti, A.D., Asia, L., Malleret, L., Mille, G., Jamoussi, B., Abderrabba, M., Doumenq, P., 2012. Aliphatic hydrocarbons, polycyclic aromatic hydrocarbons, polychlorinated biphenyls, organochlorine, and organophosphorous pesticides in surface sediments fromthe Arc river and the Berre lagoon, France. Environ. Sci. Pollut. Res. 19, 559-576.

Kanzari, F., Syakti, A.D., Asia, L., Malleret, L., Piram, A., Mille, G., Doumenq, P., 2014. Distributions and sources of persistent organic pollutants (aliphatic hydrocarbons, PAHs, PCBs and pesticides) in surface sediments of an industrialized urban river (Huveaune), France. Sci. Total Environ. 478, 141-151.

Kilunga, P.I., Sivalingam, P., Laffite, A., Grandjean, D., Mulaji, C.K., de Alencastro, L.F., Mpiana, P.T., Poté, J., 2017. Accumulation of toxic metals and organic micro-pollutants in sediments from tropical urban rivers, Kinshasa, Democratic Republic of the Congo. Chemosphere 179, 37-48.

Kumar, V., Sinha, A.K., Rodrigues, P.P., Mubiana, V.K., Blust, R., De Boeck, G., 2015. Linking environmental heavy metal concentrations and salinity gradients with metal accumulation and their effects: a case study in 3 mussel species of Vitória Estuary and Espírito Santo Bay, Southeast Brazil. Sci. Total Environ. 523, $1-15$.

Larsen, R.K., Baker, J.E., 2003. Source apportionment of polycyclic aromatic hydrocarbons in the urban atmosphere: a comparison of three methods. Environ. Sci. Technol. 37, 1873-1881.

Lee, K.T., Tanabe, S., Koh, C.H., 2001. Distribution of organochlorine pesticides in sediments from Kyeonggi 
Bay and nearby areas, Korea. Environ. Pollut. 114, 207-213.

Levei, E., Ponta, M., Senila, M., Miclean M., Frentiu, T., 2014. Assessment of contamination and origin of metals in mining affected river sediments: a case study of the Aries River catchment, Romania. J. Serb. Chem. Soc. 79, 1019-1036.

Liu, C., Zhang, L., Fan, C., Xu, F., Chen, K., Gu, X., 2017. Temporal occurrence and sources of persistent organic pollutants in suspended particulate matter from the most heavily polluted river mouth of Lake Chaohu, China. Chemosphere 174, 39-45.

Liu, J., Xu, Y., Cheng, Y., Zhao, Y., Pan, Y., Fu, G., Dai, Y., 2017. Occurrence and risk assessment of heavy metals in sediments of the Xiangjiang River, China. Environ. Sci. Pollut. Res. 24, 2711-2723.

Liu, J., Xu, Y., Cheng, Y., Zhao, Y., Pan, Y., Fu, G., Dai, Y., 2017. Occurrence and risk assessment of heavy metals in sediments of the Xiangjiang River, China. Environ. Sci. Pollut. Res. 24, 2711-2723.

Liu, M., Cheng, S., Ou, D., Yang, Y., Liu, H., Hou, L., Gao, L., Xu, S., 2008. Organochlorine pesticides in surface sediments and suspended particulate matters from the Yangtze estuary, China. Environ. Pollut. $156,168-173$.

Liu, Y., Chen, L., Huang, Q.H., Li, W.Y., Tang, Y.J., Zhao, J.F., 2009. Source apportionment of polycyclic aromatic hydrocarbons (PAHs) in surface sediments of the Huangpu River, Shanghai, China. Sci. Total. Environ. 407, 2931-2938.

Long, E.R., 2006. Calculation and uses of mean sediment quality guideline quotients: a critical review. Environ. Sci. Technol. 40, 1726-1736.

Long, E.R., MacDonald, D.D., Smith, S.L., Calder, F.D., 1995. Incidence of adverse biological effects within ranges of chemical concentrations in marine and estuarine sediments. Environ. Manag. 19, 81-97.

Lv, J., Zhang, Y., Zhao, X., Zhou, C., Guo, C., Luo, Y., Meng, W., Zou, G., Xu, J., 2015. Polybrominated diphenyl ethers (PBDEs) and polychlorinated biphenyls (PCBs) in sediments of Liaohe River: levels, spatial and temporal distribution, possible sources, and inventory. Environ. Sci. Pollut. Res. 22, 42564264.

Mahmood, A., Malik, R.N., Li, J., Zhang, G., 2014. Levels, distribution profile, and risk assessment of polychlorinated biphenyls (PCBs) in water and sediment from two tributaries of the River Chenab, Pakistan. Environ. Sci. Pollut. Res. 21, 7847-7855. 
Manoli, E., Samara, C., Konstantinou, I., Albanis, T., 2000. Polycyclic aromatic hydrocarbons in the bulk precipitation and surface waters of Northern Greece. Chemosphere 41, 1845-1855.

Marr, L.C., Kirchstetter, T.W., Harley, R.A., Miguel, A.H., Hering, S.V., Hammond, S.K., 1999. Characterization of polycyclic aromatic hydrocarbons in motor vehicle fuels and exhaust emissions. Environ. Sci. Technol. 33, 3091-3099.

Matisoff, G., Watson, S.B., Guo, J., Duewiger, A., Steely, R., 2017. Sediment and nutrient distribution and resuspension in Lake Winnipeg. Sci. Total Environ. 75, 173-186.

Matache, M.L., David, I.G., Matache, M., Ropota, M., 2009. Seasonal variation in trace metals concentrations in the Ialomita River, Romania. Environ. Monit. Assess. 153, 273-279.

Men, B., He, M., Tan, L., Lin, C., 2014. Distributions of polychlorinated biphenyls in the Daliao River estuary of Liaodong Bay, Bohai Sea (China). Mar. Pollut. Bull. 78, 77-84.

Metcalf, R.L., 1973. A century of DDT. J. Agr. Food. Chem. 21, 511-520.

Micó, C., Recatalá, L., Peris, M., Sánchez, J., 2006. Assessing heavy metal sources in agricultural soils of an European Mediterranean area by multivariate analysis. Chemosphere 65, 863-872.

Miglioranza, K.S., Gonzalez, M., Ondarza, P.M., Shimabukuro, V.M., Isla, F.I., Fillmann, G., Aizpún, J.E., Moreno, V.J., 2013. Assessment of Argentinean Patagonia pollution: PBDEs, OCPs and PCBs in different matrices from the Río Negro basin. Sci. Total Environ. 452-453, 275-285.

Mohiuddin, K.M., Ogawa, Y., Zakir, H.M., Otomo, K., Shikazono, N., 2011. Heavy metals contamination in water and sediments of an urban river in a developing country. Int. J. Environ. Sci. Technol. 8, 723-736.

Montuori, P., Aurino, S., Garzonio, F., Triassi, M., 2016. Polychlorinated biphenyls and organochlorine pesticides in Tiber River and Estuary: Occurrence, distribution and ecological risk. Sci. Total Environ. $571,1001-1016$.

Muller, G., 1969. Index of geoaccumulation in sediments of the Rhine River. GeoJournal 2, 109-118.

Mwanamoki, P.M., Devarajan, N., Thevenon, F., Birane, N., de Alencastro, L.F., Grandjean, D., Mpiana, P.T., Prabakar, K., Mubedi, J.I., Kabele, C.G., Wildi, W., Poté, J., 2014. Trace metals and persistent organic pollutants in sediments from river-reservoir systems in Democratic Republic of Congo (DRC): Spatial distribution and potential ecotoxicological effects. Chemosphere 111, 485-492.

Naji, A., Ismail, A., 2011. Assessment of metals contamination in Klang River surface sediments by using 
different indexes. Environ. Asia 4, 30-38.

Neamtu, M., Ciumasu, I.M., Costica, N., Costica, M., Bobu, M., Nicoara, M.N., Catrinescu, C., van Slooten, K.B., De Alencastro, L.F., 2009. Chemical, biological, and ecotoxicological assessment of pesticides and persistent organic pollutants in the Bahlui River, Romania. Environ. Sci. Pollut. Res. 16, S76-S85.

Nisbet, L.C.T., Lagoy, P.K., 1992. Toxic equivalency factors (TEFs) for polycyclic aromatic hydrocarbons (PAHs). Regul. Toxicol. Pharmacol. 16, 290-300.

Odhiambo, B.K., Brown, V., Armentrout, G., Giancarlo, L.C.,Wegner, C., 2013. Sediment trace metals and PCB input history in Lake Anna, Virginia, USA. Environ. Earth. Sci. 69, 2103-2117.

Olivares-Rieumont, S., De la Rosa, D., Lima, L., Graham, D.W., Katia, D., Borroto, J., Martinez, F., Sánchez, J., 2005. Assessment of heavy metal levels in Almendares River sediments-Havana City, Cuba. Water Res. 39, 3945-3953.

Oliveira, A.H., Cavalcante, R.M., Duaví, W.C., Fernandes, G.M., Nascimento, R.F., Queiroz, M.E., Mendonça, K.V., 2016. The legacy of organochlorine pesticide usage in a tropical semi-arid region (Jaguaribe River, Ceará, Brazil): implications of the influence of sediment parameters on occurrence, distribution and fate. Sci. Total Environ. 542, 254-263.

Oyo-Ita, I.O., Oyo-Ita, O.E., Ugim, S.U., Nnaji, N.N.J., Elarbaoui, S., 2017. Source and Toxicological Assessment of Polycyclic Aromatic Hydrocarbons in Sediments fromImo River, Southeastern Nigeria. Polycycl Aromat Comp. https://doi.org/10.1080/10406638.2017.1300177.

Pan, L., Ma, J., Wang, X.1., Hou, H., 2016. Heavy metals in soils from a typical county in Shanxi Province, China: levels, sources and spatial distribution. Chemosphere 148, 248-254.

Perşoiu, I., Rădoane, M., 2011. Spatial and temporal controls on historical channel responses - study of an atypical case: Someşu Mic River, Romania. Earth Surf. Process. Landforms 36, 1391-1409.

Qian, X., Liang, B., Liu, X., Liu, X., Wang, J., Liu, F., Cui., B., 2017. Distribution, sources, and ecological risk assessment of polycyclic aromatic hydrocarbons in surface sediments from the Haihe River, a typical polluted urban river in Northern China. Environ. Sci. Pollut. Res. 24, 17153-17165.

Qiu, X., Zhu, T., Yao, B., Hu, J., Hu, S., 2005. Contribution of dicofol to the current DDT pollution in China. Environ. Sci. Technol. 39, 4385-4390.

Ravindra, K., Bencs, L., Wauters, E., Hoog, J.D., Deutsch, F., Roekens, E., Bleux, N., Berghmans, P., Grieken, 
R.V., 2006. Seasonal and site specific variation in vapour and aerosol phase PAHs over Flanders (Belgium) and their relation with anthropogenic activities. Atmos. Environ. 40, 771-785.

Resongles, E., Casiot, C., Freydier, R., Dezileau, L., Viers, J., Elbaz-Poulichet, F., 2014. Persisting impact of historical mining activity to metal ( $\mathrm{Pb}, \mathrm{Zn}, \mathrm{Cd}, \mathrm{Tl}, \mathrm{Hg}$ ) and metalloid (As, Sb) enrichment in sediments of the Gardon River, Southern France. Sci Total Environ. 481, 509-521.

Rinawati, R., Takada, H., 2017. Distribution and Source of Sedimentary Polycyclic Aromatic Hydrocarbon (PAHs) in River Sediment of Jakarta. Indones. J. Chem. 17, 394-400.

RMEWM, 2006. Romanian Ministry of Environment and Water Management, Ministerial Order No. 161/2006 for the approval of the Normative regarding the surface water quality classification in order to establish the ecological status of water bodies, Official Gazette, part I. p. 511.

Sazykin, I.S., Sazykina, M.A., Khammami, M.I., Kostina, N.V., Khmelevtsova, L.E., Trubnik, R.G., 2015. Distribution of polycyclic aromatic hydrocarbons in surface sediments of lower reaches of the Don River (Russia) and their ecotoxicologic assessment by bacterial lux-biosensors. Environ. Monit. Assess. 187:277.

Shi, Z., Tao, S., Pan, B., Liu, W., Shen,W., 2007. Partitioning and source diagnostics of polycyclic aromatic hydrocarbons in rivers in Tianjin, China. Environ. Pollut. 146, 492-500.

Soclo, H.H., Garrigues, P., Ewald, M., 2000. Origin of Polycyclic Aromatic Hydrocarbons (PAHs) in Coastal Marine Sediments: Case Studies in Cotonou (Benin) and Aquitaine (France) Areas. Mar. Pollut. Bull. 40, $387-396$.

Souza, M.R.R., Santos, E., Suzarte, J.S., Carmo, L.O., Frena, M., Damasceno, F.C., Alexandre, M.R., 2018. Concentration, distribution and source apportionment of polycyclic aromatic hydrocarbons (PAH) in Poxim River sediments, Brazil. Mar. Pollut. Bull. 127, 478-483.

STAS 1913/5-85, EN 14688-2 and SR, 2005. Determination of grain size-sedimentation and sift method, National Standard - Official Edition, Romanian Institute of Standardization (In Romanian), p 1-16.

Su, X., Feng, J., Guo, L., Liu, Q., Sun, J., 2018. Polychlorinated biphenyls in the Yellow River of Henan section: occurrence, composition, and impact factors. Environmental Science and Pollution Research. 25, 13479-13488.

SW-846 EPAMethod 3051a, 2007. Microwave assisted acid digestion of sediments, sludges, soils, and oils, 1. 
Revision.

Syakti, A.D., Asia, L., Kanzari, F., Umasangadji, H., Malleret, L., Ternois, Y., Mille, G., Doumenq, P., 2013. Distribution of organochlorine pesticides (OCs) and polychlorinated biphenyls (PCBs) in marine sediments directly exposed to wastewater from Cortiou, Marseille. Environ. Sci. Pollut. Res. Int. 19, $1524-1535$.

Syed, J.H., Malik, R.N., Li, J., Chaemfa, C., Zhang, G., Jones, K.C., 2014. Status, distribution and ecological risk of organochlorines (OCs) in the surface sediments from the Ravi River, Pakistan. Sci. Total Environ. 472, 204-211.

Syed, J.H., Malik, R.N., Muhammad, A., 2013b. Organochlorine pesticides in surface soils and sediments from obsolete pesticides dumping site nearLahore city, Pakistan: contamination status and their distribution. Chem. Ecol. https://doi.org/10.1080/02757540.2013.829051.

Taylor, S.R., McLennan, S.M., 1995. The geochemical evolution of the continental crust. Geophysics 33, 241265.

Tongo, I., Ezemonye, L., Akpeh, K., 2017. Distribution, characterization, and human health risk assessment of polycyclic aromatic hydrocarbons (PAHs) in Ovia River, Southern Nigeria. Environ. Monit. Assess. 189:247.

Tu, Y.T., Ou, J.H., Tsang, D.C.W., Dong, C.D., Chen, C.W., Kao, C.M., 2018. Source Identification and Ecological Impact Evaluation of PAHs in Urban River Sediments: A Case Study in Taiwan. Chemosphere 194, 666-674.

UNIDO, 2008. Building the Capacity of the People's Republic of China to Implement the Stockholm Convention on POPs and Develop a National Implementation Plan. pp. 1-95.

Van-Birgelen, A.P.J.M., 1998. Hexachlorobenzene as a possible major contributor to the dioxin activity of human milk. Environ. Health Persp. 106, 683-688.

Van den Berg, M., Birnbaum, L.S., Denison, M., Vito, M.D., Farland, W., Feeley, M., Fiedler, H., Hakansson, H., Hanberg, A., Haws, L., Rose, M., Safe, S., Schrenk, D., Tohyama, C., Tritscher, A., Tuomisto, J., Tysklind, M., Walker, N., Peterson, R.E., 2006. The 2005 World Health Organization reevaluation of human and mammalian toxic equivalency factors for dioxins and dioxin-like compounds. Toxicol. Sci. 93, 223-241. 
Vanier, C., Sylvestre, M., Planas, D., 1996. Persistence and fate of PCBs in sediments of the Saint Lawrence River. Sci. Total Environ. 192, 229-244.

Viganò, L., Mascolo, G., Roscioli, C., 2015. Emerging and priority contaminants with endocrine active potentials in sediments and fish from the River Po (Italy). Environ. Sci. Pollut. Res. 22, 14050-14066.

Wang, H., Wang, J., Liu, R., Yu, W., Shen, Z., 2015. Spatial variation, environmental risk and biological hazard assessment of heavy metals in surface sediments of the Yangtze River Estuary. Mar. Pollut. Bull. 93, 250258.

Wang, W., Qin, Y., Song, D., Wang, K., 2008. Column leaching of coal and its combustion residues, Shizuishan, China. Int. J. Coal Geol. 75, 81-87.

Wan, X., Pan, X., Wang, B., Zhao, S., Hu, P., Li, F., Boulanger, B., 2011. Distributions, historical trends, and source investigation of polychlorinated biphenyls in Dianchi Lake, China. Chemosphere 85, 361-367.

Wolska, L., 2002. Miniaturised analytical procedure of determining polycyclic aromatic hydrocarbons and polychlorinated biphenyls in bottom sediments. J. Chromatogr. A 959, 173-180.

Wu, W.Z., Schramm, K.W., Henkelmann, B., Xu, Y., Yediler, A., Kettrup, A., 1997. PCDD/Fs, PCBs, HCHs, and HCB in sediments and soils of Ya-Er Lake area in China: results on residual levels and correlation to the organic carbon and the particle size. Chemosphere 34, 191-202.

Xu, X., Cao, Z., Zhang, Z., Li, R., Hu, B., 2016. Spatial distribution and pollution assessment of heavy metals in the surface sediments of the Bohai and Yellow Seas. Mar. Pollut. Bull. 110, 596-602.

Xu, Y., Guo, C.S., Luo, Y., Lv, J.P., Zhang, Y., Lin, H.X., Wang, L., Xu, J., 2016. Occurrence and distribution of antibiotics, antibiotic resistance genes in the urban rivers in Beijing, China. Environ. Pollut. 213, 833840.

Yamaguchi, C., Lee, W.Y., 2010. A cost effective, sensitive, and environmentally friendly sample preparation method for determination of polycyclic aromatic hydrocarbons in solid samples. J. Chromatogr. A 1217, 6816-6823.

Yang, Z., Shen, Z., Gao, F., Tang, Z., Niu, J., 2009. Occurrence and possible sources of polychlorinated biphenyls in surface sediments from the Wuhan reach of the Yangtze River, China. Chemosphere 74, $1522-1530$.

Yılmaz, A., Karacık, B., Yakan, S.D., Henkelmann, B., Schramm, K.W., Okay, O.S., 2016. Organic and heavy 
metal pollution in shipbreaking yards. Ocean Eng. 123, 452-457.

Yin, H.B., Gao, Y.N., Fan, C.X., 2011. Distribution, sources and ecological risk assessment of heavy metals in surface sediments from Lake Taihu, China. Environ. Res. Lett. 6, 67-81.

Yunker, M.B., Macdonald, R.W., Vingarzan, R., Mitchell, R.H., Goyette, D., Sylvestre, S., 2002. PAHs in the Fraser River basin: a critical appraisal of PAH ratios as indicators of PAH source and composition. Org. Geochem. 33, 489-515.

Yun, X., Yang, Y., Liu, M., Wang, J., 2015. Concentrations and risk assessment of polychlorinated biphenyls and polybrominated diphenyl ethers in surface sediments from the East Lake, China. Ecotoxicology 24, $172-180$.

Zhang, D., Wang, J., Ni, H., Zeng, H., 2017. Spatial-temporal and multi-media variations of polycyclic aromatic hydrocarbons in a highly urbanized river from South China. Sci. Total Environ. 581-582, 621628.

Zhang, M.K., Zheng, S.A., 2007. Competitive adsorption of $\mathrm{Cd}, \mathrm{Cu}, \mathrm{Hg}$ and $\mathrm{Pb}$ by agricultural soils of the Changjiang and Zhujiang deltas in China. J. Zhejiang Univ. Sci. A 8, 1808-1815.

Zhang, T., Yang, W.L., Chen, S.J., Shi, D.L., Zhao, H., Ding, Y., Huang, Y.R., Li, N., 2014. Yue Ren \& Bi-Xian Mai. Occurrence, sources, and ecological risks of PBDEs, PCBs, OCPs, and PAHs in surface sediments of the Yangtze River Delta city cluster, China. Environ. Monit. Assess. 186, 5285-5295.

Zhang, W., Feng, H., Chang, J., Qu, J., Xie, H., Yu, L., 2009. Heavy metal contamination in surface sediments of Yangtze River intertidal zone: an assessment from different indexes. Environ. Pollut. 157, 1533-1543.

Zhang, Z., Huang, J., Yu, G., Hong, H., 2004. Occurrence of PAHs, PCBs and organochlorine pesticides in the Tonghui River of Beijing, China. Environ. Pollut. 130, 249-261.

Zhao, X.S., Ding, J., You, H., 2014. Spatial distribution and temporal trends of polycyclic aromatic hydrocarbons (PAHs) in water and sediment from Songhua River. China Environ. Geochem. Hlth. 36, $131-143$.

Zhao, Z., Zhang, L., Wu, J., 2015. Polycyclic aromatic hydrocarbons (PAHs) and organochlorine pesticides (OCPs) in sediments from lakes along the middle-lower reaches of the Yangtze River and the Huaihe River of China. Limnol. Oceanogr. 61, 47-60.

Zheng, N., Wang, Q.C., Liang, Z.Z., Zheng, D.M., 2008. Characterization of heavy metal concentrations in the 
sediments of three freshwater rivers in Huludao City, Northeast China. Environ Pollut. 154, 135-142.

Zhou, S.S., Shao, L.Y., Yang, H.Y., Wang, C., Liu, W.P., 2012. Residues and sources recognition of polychlorinated biphenyls in surface sediments of Jiaojiang Estuary, East China Sea. Mar. Pollut. Bull. 64, 539-545.

Zuo, Q., Duan, Y.H., Yang, Y., Wang, X.J., Tao, S., 2007. Source apportionment of polycyclic aromatic hydrocarbons in surface soil in Tianjin, China. Environ. Pollut. 147, 303-310.

\section{Figure captions}

Figure 1. Spatial distribution of metals in surface sediments of the Someşu Mic River. 
Figure 2. Loading plots of the first two principal components for metals (A), PAHs (B), PCBs (C) and OCPs (D).

Figure 3. Box-and-whisker plots of spatial variations of geo-accumulation index (Igeo) and enrichment factor (EF) of selected metals and sampling sites in surface sediments of the Someşu Mic River. The bottom and top of the box are the 25th and 75th percentiles, respectively. Three horizontal bars represent 5th, 50th (the median), and 95th percentiles, and the cross is the mean.

Figure 4. Distributions of total PAH, PCB and OCP concentrations in surface sediments of the Someşu Mic River.

Figure 5. Principal component analysis (loading plots (A) and score plots (B)) and hierarchical cluster analysis (C) of chemical ( $\sum$ PAHs, $\sum$ PCBs, $\sum$ OCPs, metals) and physicochemical (T, EC, DO, $\left.\mathrm{pH}_{\mathrm{H} 2 \mathrm{O}}, \mathrm{pH}_{\mathrm{sed}}, \mathrm{TOC}, \mathrm{OM}\right)$ variables in sediments from the Someşu Mic River. T: Temperature, Sal: Salinity, EC: Electrical conductivity, DO: Dissolved Oxygen, $\mathrm{pH}_{\mathrm{H} 2 \mathrm{O}}: \mathrm{pH}$ of the water column above the sediments, $\mathrm{pH}_{\mathrm{sed}}: \mathrm{pH}$ of sediments, $\mathrm{TOC}$ : total organic carbon, OM: total organic matter, PAHs: total polycyclic aromatic hydrocarbons, PCBs: total polychlorinated biphenyls, OCPs: total organochlorine pesticides.

Figure 6. Spatial distribution of m-ERM-Q values of metals (A) and DDTs (B) in surface sediments of the Someşu Mic River.

\section{Table captions}

Table 1. Descriptive statistics for metal $\left(\mathrm{mg} \mathrm{kg}^{-1} \mathrm{dw}\right)$ and PAH $\left(\mathrm{ng} \mathrm{g}^{-1} \mathrm{dw}\right)$ concentrations in surface sediments of the Someşu Mic River.

Table 2. The classification of EF, Igeo, ERL, ERM and m-ERM-Q.

Table 3. Comparison of metal, PAH, PCB and OCP concentrations with ERL and ERM guideline values in surface sediments of the Someşu Mic River.

Table 4. Selected diagnostic ratios for PAHs and OCPs.

Table 5. Descriptive statistics for PCB and OCP concentrations $\left(\mathrm{ng} \mathrm{g}^{-1} \mathrm{dw}\right)$ in surface sediments of the Someşu Mic River. 
(A)

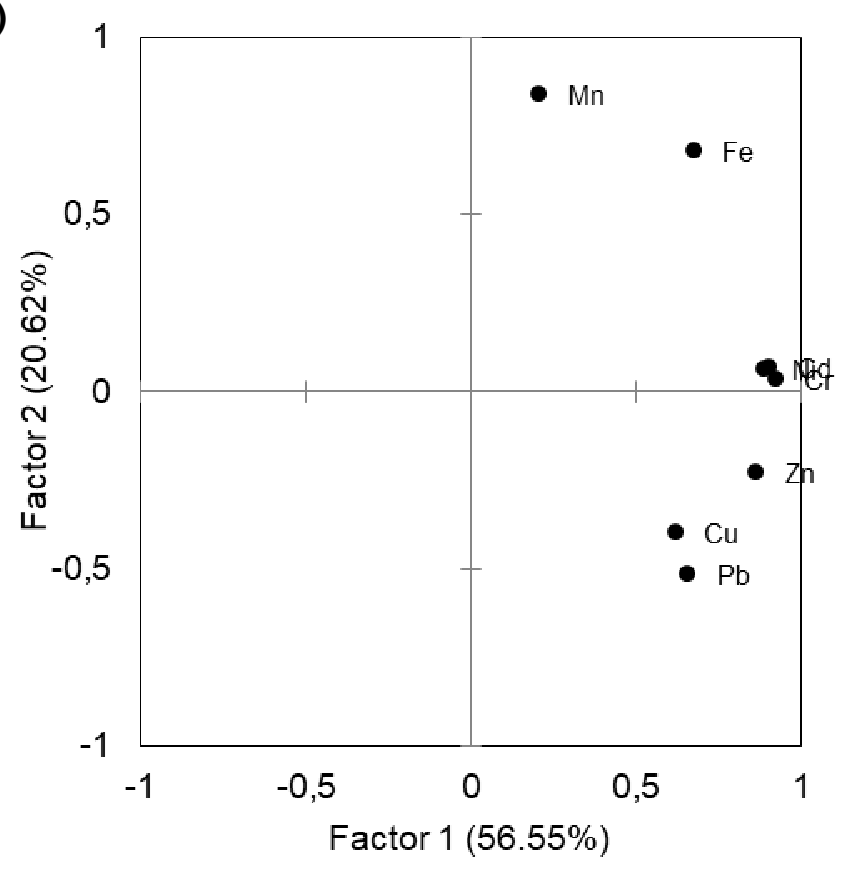

(C)

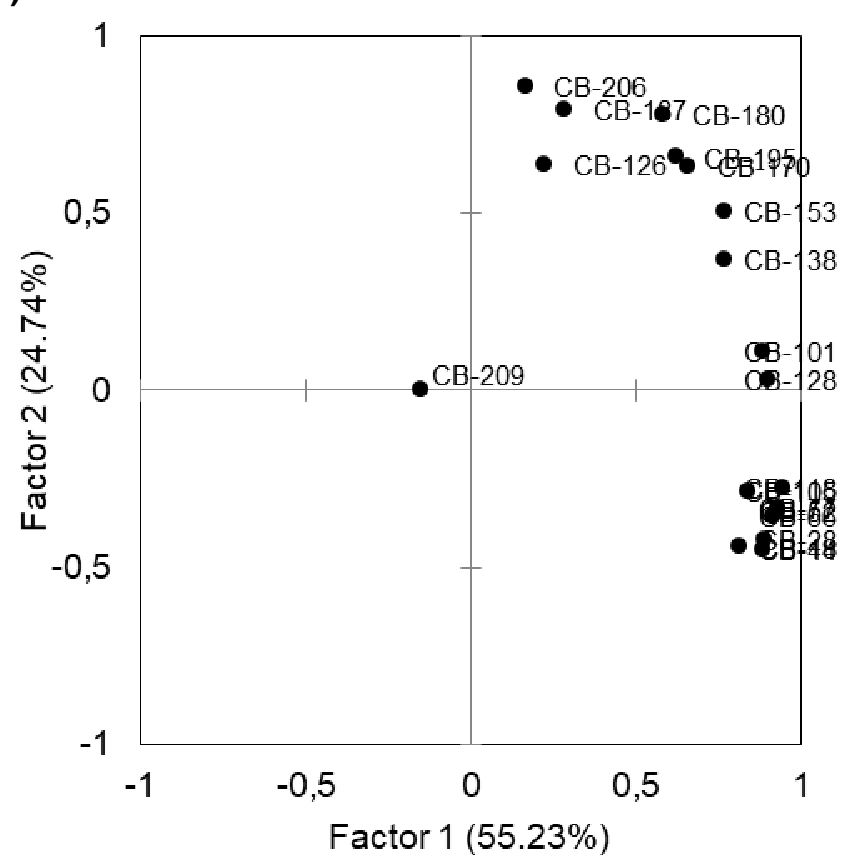

(B)

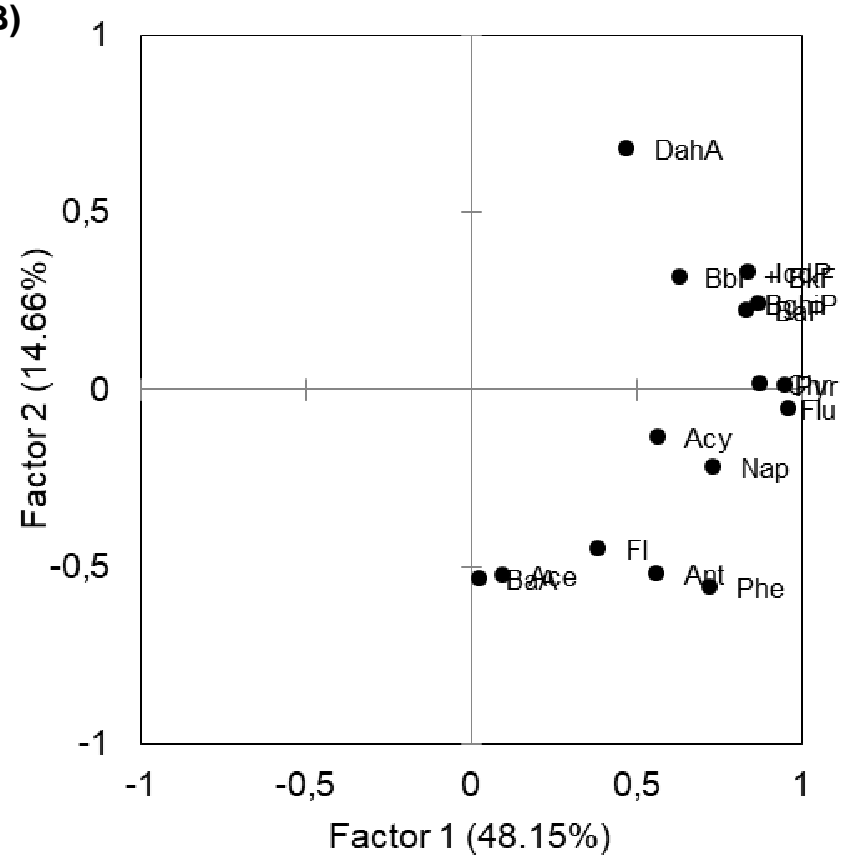

(D)

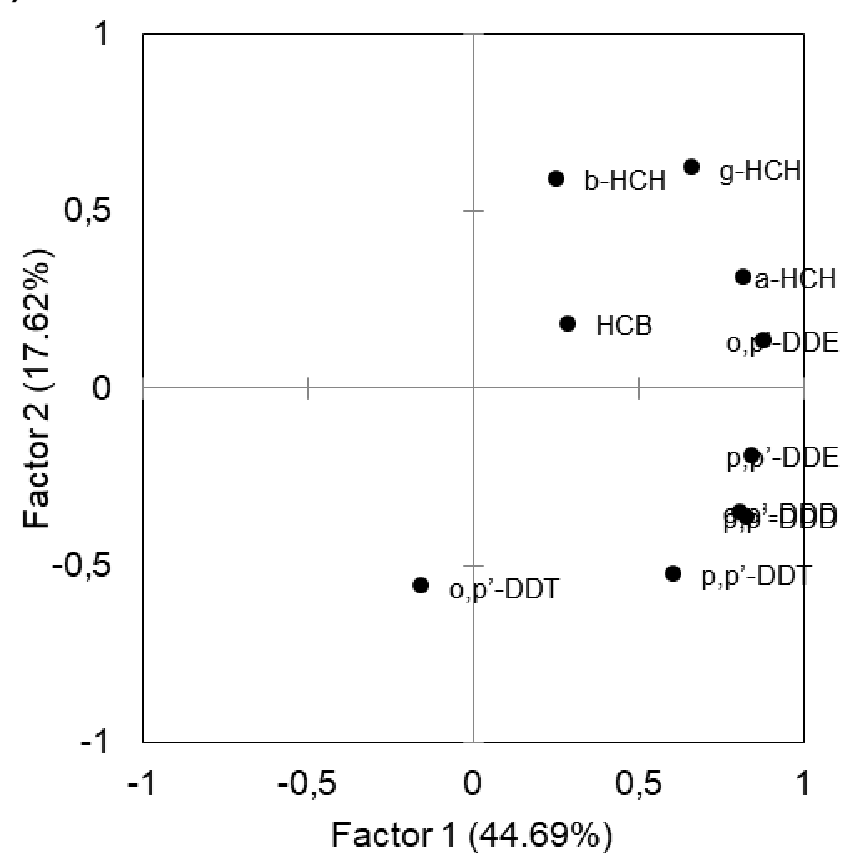

Fig. 2. Loading plots of the first two principal components for metals (A), PAHs (B), PCBs (C) and OCPs (D). 

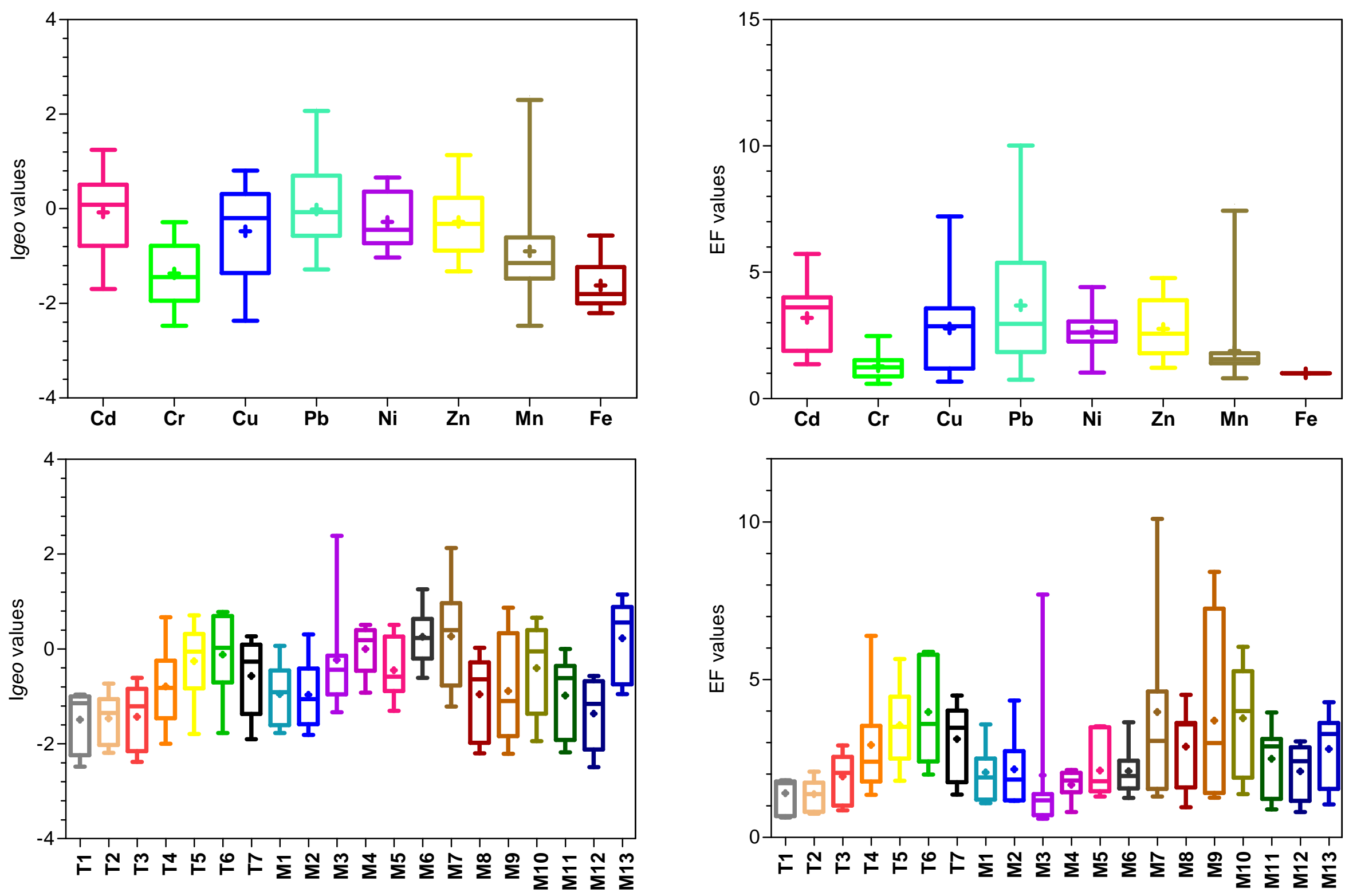

Fig. 3. Box-and-whisker plots of spatial variations of geo-accumulation index (Igeo) and enrichment factor (EF) of selected metals and sampling sites in surface sediments of the Someşu Mic River. The bottom and top of the box are the 25th and 75th percentiles, respectively. Three horizontal bars represent 5th, 50th (the median), and 95th percentiles, and the cross is the mean. 

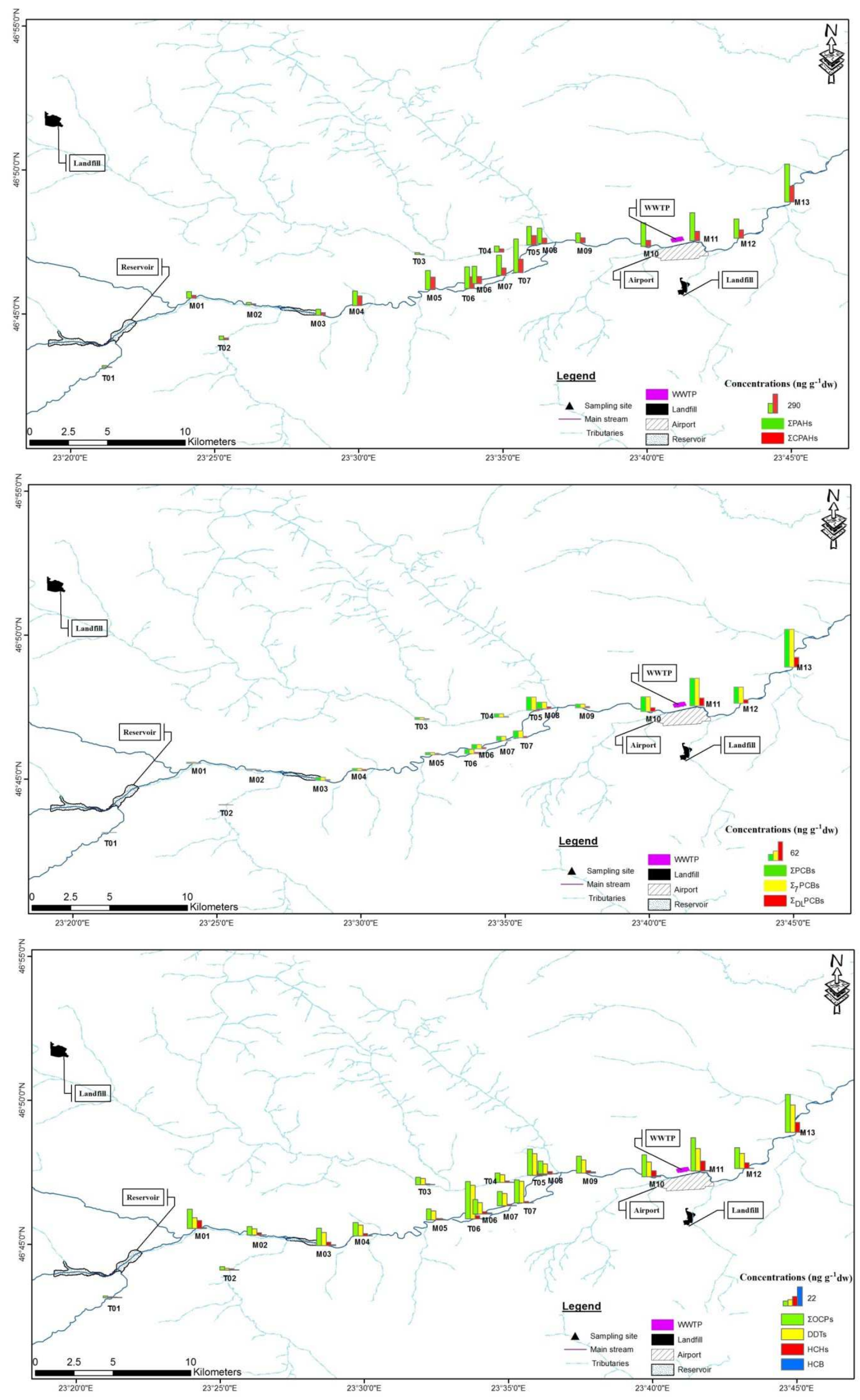

Fig. 4. Distributions of total PAH, PCB and OCP concentrations in surface sediments of the Someşu Mic River. 
(A)

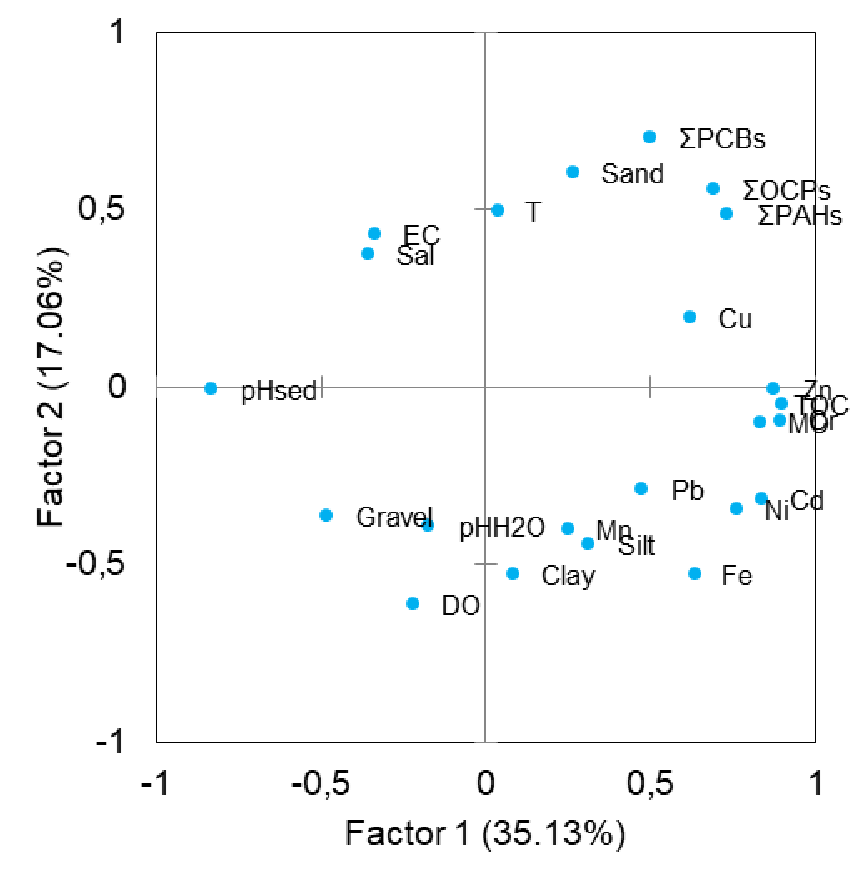

(B)

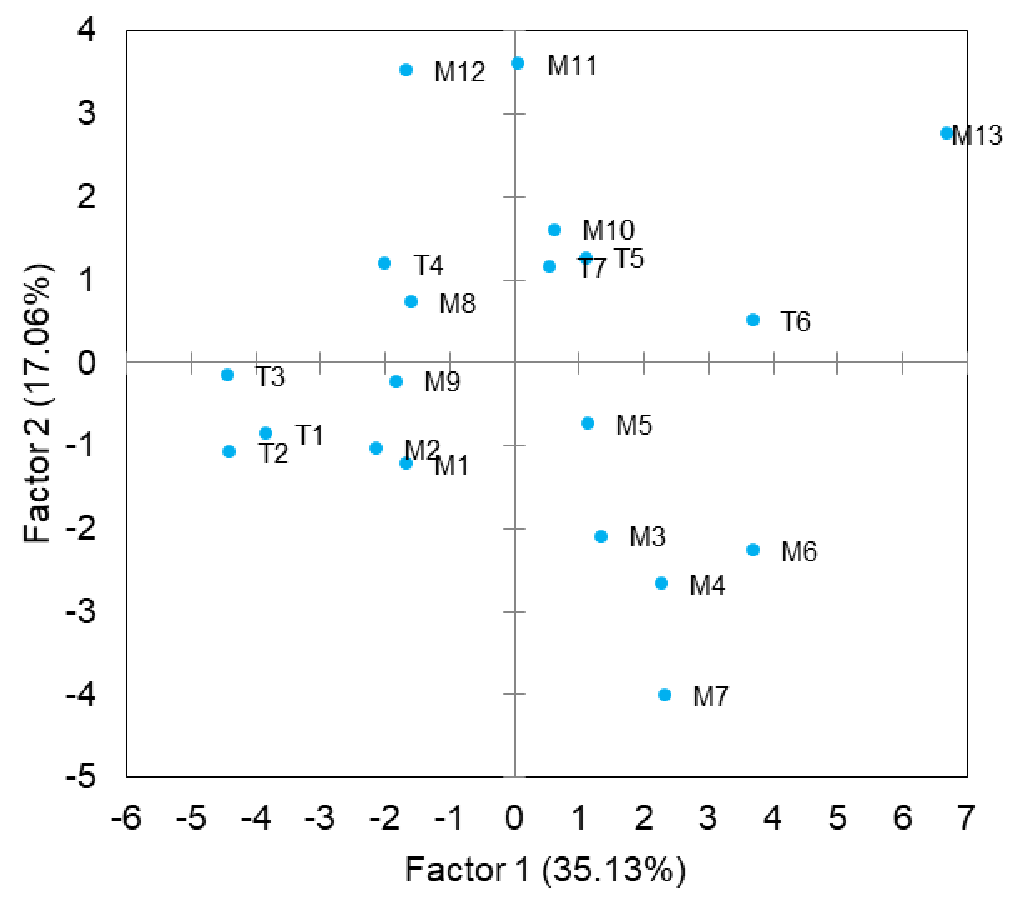

(C)

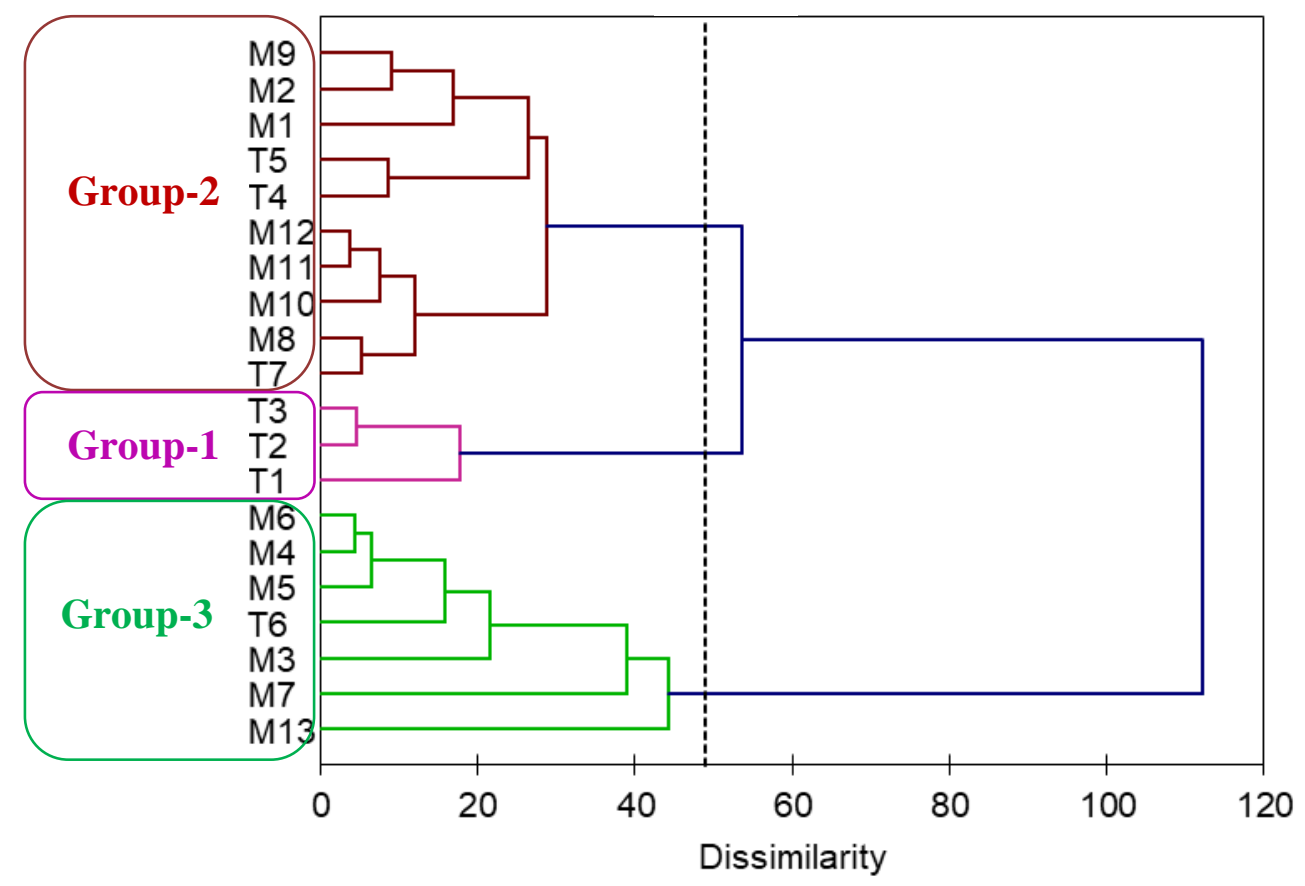

Fig. 5. Principal component analysis (loading plots (A) and score plots (B)) and hierarchical cluster analysis (C) of chemical ( $\Sigma$ PAHs, $\Sigma$ PCBs, $\Sigma O C P s$, metals) and physicochemical $\left(\mathrm{T}, \mathrm{EC}, \mathrm{DO}, \mathrm{pH}_{\mathrm{H} 2 \mathrm{O}}, \mathrm{pH}_{\mathrm{sed}}, \mathrm{TOC}, \mathrm{OM}\right.$ ) variables in sediments from the Someşu Mic River. T: Temperature, Sal: Salinity, EC: Electrical conductivity, DO: Dissolved Oxygen, $\mathrm{pH}_{\mathrm{H} 2 \mathrm{O}}$ : $\mathrm{pH}$ of the water column above the sediments, $\mathrm{pH}_{\text {sed }}$ : $\mathrm{pH}$ of sediments, $\mathrm{TOC}$ : total organic carbon, OM: total organic matter, PAHs: total polycyclic aromatic hydrocarbons, PCBs: total polychlorinated biphenyls, OCPs: total organochlorine pesticides. 
(A)
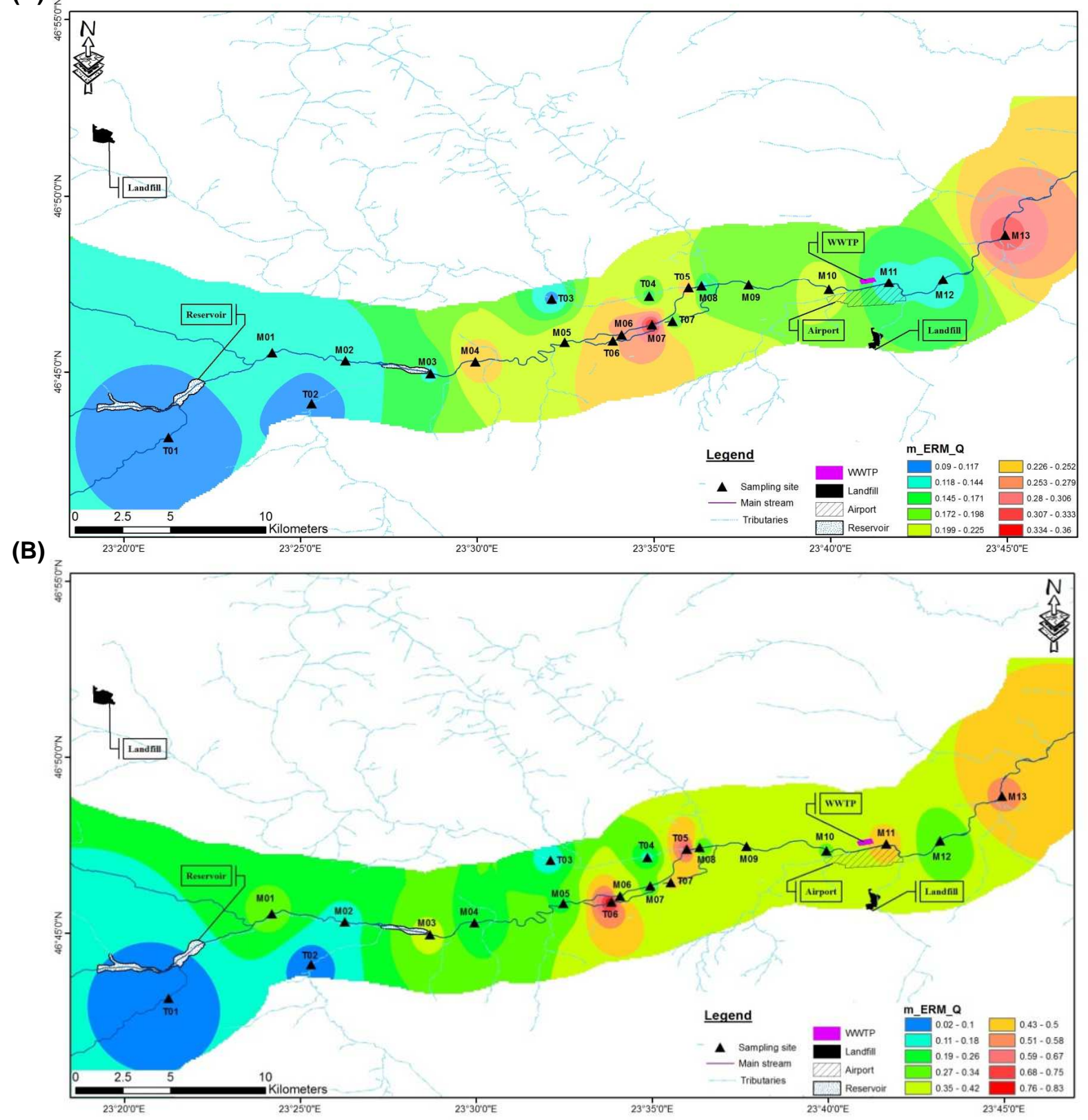

Fig. 6. Spatial distribution of $m-E R M-Q$ values of metals $(A)$ and DDTs (B) in surface sediments of the Someşu Mic River. 


\section{Table 1}

Descriptive statistics for metal $\left(\mathrm{mg} \mathrm{kg}^{-1} \mathrm{dw}\right.$ ) and PAH $\left(\mathrm{ng} \mathrm{g}^{-1} \mathrm{dw}\right)$ concentrations in surface sediments of the Someşu Mic River.

\begin{tabular}{|c|c|c|c|c|c|c|c|c|c|}
\hline & Min & Median & $\operatorname{Max}$ & Mean & SD & CV $(\%)^{a}$ & $\mathrm{DR}(\%)$ & Background $^{b}$ & $\mathrm{RL}^{c}$ \\
\hline \multicolumn{10}{|l|}{ Metals } \\
\hline $\mathrm{Cd}$ & 0.04 & 0.16 & 0.35 & 0.16 & 0.08 & 52.57 & 100 & 0.098 & 0.8 \\
\hline $\mathrm{Cr}$ & 9.39 & 19.33 & 43.15 & 22.62 & 10.51 & 46.46 & 100 & & 100 \\
\hline $\mathrm{Cu}$ & 7.22 & 32.69 & 65.56 & 32.62 & 18.01 & 55.20 & 100 & & 40 \\
\hline $\mathrm{Pb}$ & 12.27 & 28.65 & 131.39 & 35.51 & 26.43 & 74.42 & 100 & 20 & 85 \\
\hline $\mathrm{Ni}$ & 14.73 & 22.09 & 47.69 & 26.58 & 10.69 & 40.21 & 100 & 20 & 35 \\
\hline $\mathrm{Zn}$ & 42.12 & 85.24 & 236.82 & 97.71 & 50.10 & 51.27 & 100 & 71 & 150 \\
\hline $\mathrm{Mn}$ & 159.90 & 406.00 & 4707.21 & 694.80 & 982.70 & 141.44 & 100 & 600 & - \\
\hline $\mathrm{Fe}$ & 11359.44 & 15102.00 & 35661.28 & 18410.76 & 8177.45 & 44.42 & 100 & 35000 & - \\
\hline$\Sigma$ Metals & 11881.34 & 15609.00 & 40541.56 & 19320.78 & 8924.12 & 46.19 & & & \\
\hline \multicolumn{10}{|l|}{ PAHs } \\
\hline Nap & $<$ lod & 6.99 & 41.61 & 9.16 & 9.29 & 101.48 & 95 & & \\
\hline Acy & 0.14 & 1.44 & 4.93 & 1.74 & 1.28 & 73.54 & 100 & & \\
\hline Ace & 0.34 & 2.66 & 10.65 & 3.31 & 2.50 & 75.34 & 100 & & \\
\hline $\mathrm{FI}$ & 0.57 & 5.80 & 13.11 & 5.62 & 3.44 & 61.11 & 100 & & \\
\hline Phe & $<$ lod & 18.16 & 90.50 & 26.85 & 24.17 & 90.01 & 95 & & \\
\hline Ant & $<$ lod & $<$ lod & 8.89 & 1.69 & 2.93 & 173.46 & 30 & & \\
\hline Flu & 1.96 & 29.91 & 98.09 & 36.10 & 30.79 & 85.29 & 100 & & \\
\hline Pyr & 1.36 & 25.59 & 99.58 & 33.03 & 30.19 & 91.39 & 100 & & \\
\hline $\mathrm{BaA}$ & $<$ lod & $<$ lod & 7.63 & 0.38 & 1.71 & 447.21 & 5 & & \\
\hline Chr & 1.20 & 29.10 & 88.82 & 31.56 & 24.74 & 78.38 & 100 & & \\
\hline $\mathrm{BbF}+\mathrm{BkF}$ & 0.47 & 33.75 & 117.36 & 41.77 & 34.44 & 82.45 & 100 & & \\
\hline $\mathrm{BaP}$ & $<\operatorname{lod}$ & 7.13 & 44.92 & 10.34 & 11.23 & 108.62 & 95 & & \\
\hline DahA & 0.80 & 6.44 & 18.58 & 7.21 & 5.52 & 76.66 & 100 & & \\
\hline IcdP & 0.25 & 8.12 & 31.30 & 9.52 & 7.38 & 77.49 & 100 & & \\
\hline BghiP & 0.77 & 13.33 & 58.29 & 14.92 & 13.38 & 89.70 & 100 & & \\
\hline ¿CPAHs ${ }^{d}$ & 2.72 & 98.75 & 242.10 & 100.78 & 70.35 & 69.80 & & & \\
\hline$\Sigma \mathrm{PAHs}$ & 24.78 & 250.20 & 575.62 & 233.20 & 161.33 & 69.18 & & & \\
\hline
\end{tabular}

$<$ lod: below the limit of detection.

${ }^{a} \mathrm{CV}$ : coefficient of variation, $\mathrm{CV}=$ standard deviation/mean (\%).

${ }^{\mathrm{b}}$ Upper continental crust background values from Taylor and McLennan (1995).

${ }^{c}$ Romanian legislation (RMEWM, 2006).

${ }^{a}$ Sum concentration of seven carcinogenic PAHs (BaA, Chr, BbF, BkF, BaP, DahA, and IcdP). 


\section{Table 2}

The classification of EF, Igeo, ERL, ERM and m-ERM-Q.

\begin{tabular}{|c|c|c|c|c|c|c|}
\hline \multicolumn{2}{|l|}{$\mathrm{EF}$} & \multicolumn{3}{|l|}{ Igeo } & \multicolumn{2}{|c|}{ ERL, ERM and $m$-ERM-Q } \\
\hline Category & Description & Category & Class & Description & Category & Description \\
\hline$\overline{E F}<1$ & no enrichment & Igeo $\leq 0$ & 0 & Practically uncontaminated & $\leq$ ERL & Effects rarely occur \\
\hline $\mathrm{EF}<3$ & minor enrichment & $0<$ Igeo $<1$ & 1 & unpolluted to moderately contaminated & $>$ ERL, $\leq$ ERM & Effects occasionally occur \\
\hline $3<\mathrm{EF}<5$ & moderate enrichment & $1<$ Igeo $<2$ & 2 & moderately contaminated & >ERM & Effects frequently occur \\
\hline $5<\mathrm{EF}<10$ & moderately severe enrichment & $2<$ Igeo $<3$ & 3 & moderately to strongly contaminated & m-ERM-Q $\leq 0.1$ & $9 \%$ probability of toxicity \\
\hline $10<\mathrm{EF}<25$ & severe enrichment & $3<$ Igeo $<4$ & 4 & strongly contaminated & $0.1<\mathrm{m}-\mathrm{ERM}-\mathrm{Q} \leq 0.5$ & $21 \%$ probability of toxicity \\
\hline $25<\mathrm{EF}<50$ & very severe enrichment & $4<$ Igeo $<5$ & 5 & strongly to extremely contaminated & $0.5<\mathrm{m}-\mathrm{ERM}-\mathrm{Q} \leq 1.5$ & $49 \%$ probability of toxicity \\
\hline $\mathrm{EF}>50$ & extremely severe enrichment & Igeo $>5$ & 6 & extremely contaminated & m-ERM-Q > 1.5 & $76 \%$ probability of toxicity \\
\hline
\end{tabular}




\section{Table 3}

Comparison of metal, PAH, PCB and OCP concentrations with ERL and ERM guideline values in surface sediments of the Someşu Mic River.

\begin{tabular}{|c|c|c|c|c|c|c|}
\hline \multirow{2}{*}{ Compounds } & \multirow{2}{*}{$E R L^{a}$} & \multirow{2}{*}{$\mathrm{ERM}^{\mathrm{a}}$} & \multirow{2}{*}{$\begin{array}{l}\text { Concentration } \\
\text { ranges }\end{array}$} & \multicolumn{3}{|c|}{ Number of sampling sites } \\
\hline & & & & $<\mathrm{ERL}$ & ERL-ERM & $>$ ERM \\
\hline \multicolumn{7}{|l|}{ Metals ${ }^{b}$} \\
\hline $\mathrm{Cd}$ & 1.20 & 9.60 & $0.06-0.29$ & 20 & 0 & 0 \\
\hline $\mathrm{Cr}$ & 81.0 & 370 & $10.07-43.15$ & 20 & 0 & 0 \\
\hline $\mathrm{Cu}$ & 34.0 & 270 & $7.22-65.56$ & 10 & 10 & 0 \\
\hline $\mathrm{Pb}$ & 46.7 & 218 & $12.27-54.65$ & 14 & 6 & 0 \\
\hline $\mathrm{Ni}$ & 20.9 & 51.6 & $14.73-47.69$ & 8 & 12 & 0 \\
\hline $\mathrm{Zn}$ & 150 & 410 & $42.12-236.82$ & 18 & 2 & 0 \\
\hline \multicolumn{7}{|l|}{ PAHs $^{\circ}$} \\
\hline Nap & 160 & 2100 & $<\mathrm{lod}-41.61$ & 20 & 0 & 0 \\
\hline Acy & 44 & 640 & $0.14-4.93$ & 20 & 0 & 0 \\
\hline Ace & 16 & 500 & $0.34-10.65$ & 20 & 0 & 0 \\
\hline $\mathrm{FI}$ & 19 & 540 & $0.57-9.64$ & 20 & 0 & 0 \\
\hline Phe & 240 & 1500 & $<$ lod-90.50 & 20 & 0 & 0 \\
\hline Ant & 85.3 & 1100 & $<$ lod-8.89 & 20 & 0 & 0 \\
\hline Flu & 600 & 5100 & $1.96-98.09$ & 20 & 0 & 0 \\
\hline Pyr & 665 & 2600 & $1.36-99.58$ & 20 & 0 & 0 \\
\hline $\mathrm{BaA}$ & 261 & 1600 & $<$ lod-7.63 & 20 & 0 & 0 \\
\hline Chr & 384 & 2800 & $1.20-88.82$ & 20 & 0 & 0 \\
\hline $\mathrm{BaP}$ & 430 & 1600 & $<$ lod-44.92 & 20 & 0 & 0 \\
\hline DahA & 63.4 & 260 & $0.80-18.58$ & 20 & 0 & 0 \\
\hline$\Sigma \mathrm{PAHs}$ & 4022 & 44,792 & $24.78-575.62$ & 20 & 0 & 0 \\
\hline \multicolumn{7}{|l|}{ PCBs $^{\circ}$} \\
\hline$\Sigma \mathrm{PCB}$ & 22.7 & 180 & 2.74-252.72 & 9 & 10 & 1 \\
\hline \multicolumn{7}{|l|}{ OCPs ${ }^{\circ}$} \\
\hline$p, p^{\prime}-\mathrm{DDE}$ & 2.2 & 27 & $0.02-12.00$ & 6 & 14 & 0 \\
\hline$p, p^{\prime}-\mathrm{DDD}$ & 2.1 & 20 & $0.58-12.02$ & 3 & 17 & 0 \\
\hline$p, p^{\prime}-\mathrm{DDT}$ & 1.3 & 7.1 & $0.25-12.29$ & 2 & 16 & 2 \\
\hline ¿DDT & 1.6 & 46.1 & $1.00-39.24$ & 1 & 19 & 0 \\
\hline
\end{tabular}

a Values taken from Long et al. (1995).

${ }^{\mathrm{b}}$ Concentrations in $\mathrm{mg} \mathrm{Kg}^{-1} \mathrm{dw}$.

${ }^{c}$ Concentrations in $\mathrm{ng} \mathrm{g}^{-1} \mathrm{dw}$. 


\section{Table 4}

Selected diagnostic ratios for PAHs and OCPs.

\begin{tabular}{|c|c|c|c|c|c|c|c|c|c|}
\hline \multirow[t]{2}{*}{ Sites } & \multicolumn{5}{|l|}{$\mathrm{PAHs}$} & \multicolumn{4}{|l|}{ OCPs } \\
\hline & Flu/(Flu+Pyr) & IcdP/(IcdP+BghiP) & $\mathrm{BaP} / \mathrm{BghiP}$ & $\mathrm{LMW} / \mathrm{HMW}^{\mathrm{a}}$ & $\mathrm{C}^{*} \mathrm{PAHs} / \Sigma \mathrm{PAHs}{ }^{b}$ & $o, p^{\prime}-\mathrm{DDT} / p, p^{\prime}-\mathrm{DDT}$ & $\alpha-\mathrm{HCH} / \gamma-\mathrm{HCH}$ & $(\mathrm{DDE}+\mathrm{DDD}) / \Sigma \mathrm{DDT}$ & DDD/DDE \\
\hline $\mathrm{T1}$ & 0.51 & 0.35 & 0.90 & 1.30 & 0.36 & 0.49 & 5.13 & 0.62 & 25.42 \\
\hline T2 & 0.45 & 0.64 & 1.22 & 0.45 & 0.54 & 0.53 & 5.18 & 0.72 & 1.95 \\
\hline T3 & 0.63 & 0.25 & 0.00 & 2.43 & 0.26 & 0.05 & 2.07 & 0.75 & 1.24 \\
\hline T4 & 0.73 & 0.42 & 0.99 & 0.08 & 0.91 & 0.20 & 6.34 & 0.80 & 0.76 \\
\hline T5 & 0.47 & 0.41 & 0.56 & 0.22 & 0.81 & 0.06 & 15.49 & 0.49 & 1.33 \\
\hline T6 & 0.51 & 0.38 & 0.25 & 0.09 & 0.86 & 0.05 & 9.33 & 0.72 & 1.21 \\
\hline T7 & 0.50 & 0.35 & 0.77 & 0.11 & 0.88 & 0.07 & 3.61 & 0.78 & 1.12 \\
\hline M1 & 0.49 & 0.38 & 0.53 & 0.47 & 0.63 & 0.08 & 3.00 & 0.64 & 1.02 \\
\hline M2 & 0.46 & 0.31 & 0.02 & 0.37 & 0.69 & 0.13 & 17.23 & 0.60 & 1.52 \\
\hline M3 & 0.50 & 0.52 & 0.63 & 0.35 & 0.67 & 0.04 & 3.79 & 0.59 & 1.12 \\
\hline M4 & 0.54 & 0.67 & 0.82 & 0.10 & 0.88 & 0.00 & 6.06 & 0.86 & 0.93 \\
\hline M5 & 0.60 & 0.39 & 1.49 & 0.15 & 0.80 & 0.16 & 16.97 & 0.63 & 1.59 \\
\hline M6 & 0.52 & 0.34 & 0.19 & 0.35 & 0.73 & 0.00 & 2.97 & 0.65 & 1.90 \\
\hline M7 & 0.50 & 0.34 & 0.36 & 0.38 & 0.70 & 0.00 & 12.00 & 0.71 & 0.81 \\
\hline M8 & 0.49 & 0.25 & 0.60 & 0.33 & 0.72 & 0.32 & 4.67 & 0.58 & 1.61 \\
\hline M9 & 0.45 & 0.33 & 0.40 & 0.24 & 0.71 & 0.08 & 8.69 & 0.62 & 2.23 \\
\hline M10 & 0.49 & 0.40 & 0.41 & 0.36 & 0.73 & 0.00 & 17.08 & 0.76 & 1.15 \\
\hline M11 & 0.62 & 0.37 & 0.90 & 0.40 & 0.70 & 0.00 & 4.72 & 0.80 & 0.82 \\
\hline M12 & 0.59 & 0.40 & 1.83 & 0.45 & 0.68 & 0.00 & 26.27 & 0.90 & 0.43 \\
\hline M13 & 0.49 & 0.39 & 1.08 & 0.24 & 0.78 & 0.00 & 8.01 & 0.84 & 0.79 \\
\hline Average & 0.53 & 0.39 & 0.70 & 0.44 & 0.70 & 0.11 & 8.93 & 0.70 & 2.45 \\
\hline Origin & Pyrolytic & Fuel combustion & Petrogenic & Pyrolytic & Combustion & Technical DDTs & Technical HCHs & Historical & $\begin{array}{l}\text { Anaerobic } \\
\text { degradation }\end{array}$ \\
\hline
\end{tabular}

a $\mathrm{LMW} / \mathrm{HMW}$ : the ratio of the sum of 2 and 3-ring $\mathrm{PAHs}$ divided by the sum of 4 to 6-ring PAHs.

${ }^{\mathrm{b}} \mathrm{C}^{*} \mathrm{PAH}=\mathrm{Flu}+\mathrm{Pyr}+\mathrm{BaA}+\mathrm{Chr}+\mathrm{BbF}+\mathrm{BkF}+\mathrm{BaP}+\mathrm{lcdP}+\mathrm{BghiP}$. 
1 Table 5

2 Descriptive statistics for PCB and OCP concentrations (ng $g^{-1} \mathrm{dw}$ ) in surface sediments of the

3 Someşu Mic River.

\begin{tabular}{|c|c|c|c|c|c|c|c|}
\hline Compound & Min & Median & Max & Mean & SD & CV $(\%)^{a}$ & DR (\%) \\
\hline $\begin{array}{l}\text { PCBs } \\
D i-C B s\end{array}$ & & & & & & & \\
\hline $\begin{array}{l}\text { CB-8 } \\
\text { Tri-CBs }\end{array}$ & $<$ lod & $<$ lod & $<$ lod & $<$ lod & $<$ lod & $<$ lod & 0 \\
\hline CB-18 & 0.20 & 1.59 & 31.42 & 4.58 & 7.09 & 154.91 & 100 \\
\hline $\begin{array}{l}\text { CB-28 } \\
\text { Tetra-CBs }\end{array}$ & 0.23 & 2.46 & 75.83 & 12.19 & 19.94 & 163.65 & 100 \\
\hline CB-52 & $<$ lod & 1.41 & 24.02 & 4.13 & 6.27 & 151.89 & 10 \\
\hline CB-44 & 0.04 & 1.05 & 24.36 & 3.72 & 6.21 & 166.77 & 100 \\
\hline CB-66 & 0.27 & 1.78 & 47.78 & 6.77 & 12.13 & 179.25 & 100 \\
\hline $\begin{array}{l}\text { CB-77 } \\
\text { Penta-CBs }\end{array}$ & 0.03 & 2.35 & 20.06 & 4.24 & 5.31 & 125.37 & 100 \\
\hline CB-101 & 0.05 & 1.16 & 5.50 & 1.64 & 1.57 & 96.05 & 100 \\
\hline CB-105 & $<$ lod & 0.49 & 3.58 & 0.87 & 0.98 & 113.28 & 95 \\
\hline CB-118 & $<$ lod & 0.92 & 9.93 & 1.71 & 2.42 & 141.44 & 95 \\
\hline $\begin{array}{l}\text { CB-126 } \\
\text { Hexa-CBs }\end{array}$ & $<$ lod & $<$ lod & 1.24 & 0.14 & 0.32 & 224.83 & 35 \\
\hline CB-128 & $<$ lod & $<$ lod & 1.13 & 0.23 & 0.38 & 160.15 & 30 \\
\hline CB-138 & 0.12 & 1.86 & 5.47 & 2.23 & 1.76 & 79.23 & 100 \\
\hline $\begin{array}{l}\text { CB-153 } \\
\text { Hepta-CBs }\end{array}$ & 0.10 & 1.45 & 6.69 & 2.05 & 1.95 & 95.25 & 100 \\
\hline CB-170 & $<$ lod & 0.63 & 2.78 & 0.84 & 0.83 & 98.41 & 75 \\
\hline $\begin{array}{l}\text { CB-180 } \\
\text { Octa-CBs }\end{array}$ & 0.04 & 0.75 & 5.27 & 1.40 & 1.65 & 117.75 & 100 \\
\hline $\begin{array}{l}\text { CB-195 } \\
\text { Nona-CBs }\end{array}$ & $<$ lod & 0.07 & 0.43 & 0.11 & 0.13 & 120.54 & 55 \\
\hline $\begin{array}{l}\text { CB-206 } \\
\text { Deca-CBs }\end{array}$ & $<$ lod & $<$ lod & 0.21 & 0.03 & 0.07 & 212.83 & 15 \\
\hline CB-187 & $<$ lod & 0.53 & 2.96 & 0.88 & 0.94 & 107.12 & 95 \\
\hline CB-209 & $<$ lod & $<$ lod & 0.05 & $<$ lod & 0.01 & 311.59 & 95 \\
\hline$\Sigma_{7} \mathrm{PCBs}^{\mathrm{b}}$ & 0.60 & 13.24 & 123.51 & 25.34 & 32.26 & 127.34 & \\
\hline$\Sigma_{D L} P C B s$ & 0.07 & 4.27 & 32.88 & 6.96 & 8.54 & 122.69 & \\
\hline$\Sigma \mathrm{PCBs}$ & 2.74 & 23.62 & 252.72 & 47.76 & 63.71 & 133.39 & \\
\hline Pesticides & & & & & & & \\
\hline $\mathrm{HCB}$ & 0.19 & 0.47 & 1.33 & 0.58 & 0.36 & 61.83 & 100 \\
\hline$\alpha-\mathrm{HCH}$ & 0.62 & 2.10 & 10.36 & 3.24 & 2.78 & 85.78 & 100 \\
\hline$\beta-\mathrm{HCH}$ & $<$ lod & $<$ lod & 2.28 & 0.35 & 0.58 & 166.69 & 40 \\
\hline$\gamma-\mathrm{HCH}$ & 0.10 & 0.96 & 1.86 & 0.49 & 0.52 & 105.30 & 100 \\
\hline$\delta-\mathrm{HCH}$ & $<$ lod & $<$ lod & $<$ lod & $<$ lod & $<$ lod & $<$ lod & 0 \\
\hline$o, p^{\prime}-\mathrm{DDE}$ & $<$ lod & 0.61 & 3.32 & 0.94 & 0.93 & 98.20 & 90 \\
\hline$p, p^{\prime}-\mathrm{DDE}$ & 0.02 & 3.67 & 12.00 & 4.62 & 3.59 & 77.70 & 100 \\
\hline$o, p^{\prime}-\mathrm{DDD}$ & 0.02 & 1.61 & 4.21 & 1.76 & 1.29 & 73.03 & 100 \\
\hline$p, p^{\prime}-\mathrm{DDD}$ & 0.58 & 3.67 & 12.02 & 4.04 & 2.65 & 65.70 & 100 \\
\hline$o, p^{\prime}-\mathrm{DDT}$ & $<$ lod & 0.23 & 1.20 & 0.27 & 0.31 & 114.87 & 65 \\
\hline$p, p^{\prime}-\mathrm{DDT}$ & 0.25 & 4.17 & 12.29 & 4.19 & 3.00 & 71.48 & 100 \\
\hline$\Sigma \mathrm{HCHs}$ & 0.77 & 2.71 & 11.87 & 4.08 & 3.38 & 82.80 & \\
\hline ¿DDTs & 1.00 & 13.78 & 39.24 & 15.82 & 9.71 & 61.39 & \\
\hline$\Sigma O C P s$ & 2.07 & 18.21 & 44.28 & 20.48 & 12.01 & 58.64 & \\
\hline
\end{tabular}


